\title{
DJ-1 glyoxalase activity makes a modest contribution to cellular defense against methylglyoxal damage in neurons
}

Melissa Conti Mazza*1, Sarah Shuck*2, Jiusheng Lin ${ }^{3}$, Michael A. Moxley ${ }^{4}$, John Termini², Mark R. Cookson ${ }^{1}$, Mark A. Wilson ${ }^{3}$

1. Cell Biology and Gene Expression Section, National Institute on Aging, National Institutes of Health, Bethesda, Maryland, USA

2. Department of Molecular Medicine, Beckman Research Institute at City of Hope, Duarte, California, USA

3. Department of Biochemistry and Redox Biology Center, University of Nebraska, Lincoln, Nebraska, USA

4. Department of Chemistry, University of Nebraska at Kearney, Kearney, Nebraska, USA

*These authors contributed equally to this work

To whom correspondence may be addressed: MRC: cookson@mail.nih.gov, JT: jtermini@coh.org, MAW: mwilson13@unl.edu

Running Title: Minor role for DJ-1 glyoxalase activity in neurons

Keywords: PARK7, Parkinson's disease, glycation stress, deglycase, glyoxalase, enzyme mechanism 


\begin{abstract}
Human DJ-1 is a cytoprotective protein whose absence causes Parkinson's disease and is also associated with other diseases. DJ-1 has an established role as a redox-regulated protein that defends against oxidative stress and mitochondrial dysfunction. Multiple studies have suggested that DJ-1 is also a protein/nucleic acid deglycase that plays a key role in the repair of glycation damage caused by methylglyoxal (MG), a reactive $\alpha$-keto aldehyde formed by central metabolism. Contradictory reports suggest that DJ-1 is a glyoxalase but not a deglycase and does not play a major role in glycation defense. Resolving this issue is important for understanding how DJ-1 protects cells against insults that can cause disease. We find that DJ-1 reduces levels of reversible adducts of MG with guanine and cysteine in vitro. The steady-state kinetics of DJ-1 acting on reversible hemithioacetal substrates are fitted adequately with a computational kinetic model that requires only a DJ-1 glyoxalase activity, supporting the conclusion that deglycation is an apparent rather than a true activity of DJ-1. Sensitive and quantitative isotope-dilution mass spectrometry shows that DJ-1 modestly reduces the levels of some irreversible guanine and lysine glycation products in primary and cultured neuronal cell lines and whole mouse brain, consistent with a small but measurable effect on total neuronal glycation burden. However, DJ-1 does not improve cultured cell viability in exogenous MG. In total, our results suggest that DJ-1 is not a deglycase and has only a minor role in protecting neurons against methylglyoxal toxicity.
\end{abstract}




\section{Introduction}

DJ-1 is a $20 \mathrm{kDa}$ homodimeric protein that is conserved from bacteria to humans (1-3). In humans, mutations in DJ-1 (PARK7) cause rare forms of autosomal recessive parkinsonism (4). Eukaryotic DJ-1 promotes cell survival, particularly during oxidative stress or mitochondrial dysfunction, and is found in multiple cellular compartments (5-9). Consistent with its cytoprotective role, DJ-1 is highly expressed in several types of cancers $(10-14)$ and it plays important roles in maintaining normal function in lung $(15,16)$, eye $(8,17)$, and kidney $(18,19)$. A conserved cysteine (Cys106) in DJ-1 is both essential for its cytoprotective activity during oxidative stress $(5,8,9,15,20,21)$ and is oxidation-prone, forming cysteine sulfinate $\left(-\mathrm{SO}_{2}{ }^{-}\right)$and sulfonate $\left(-\mathrm{SO}_{3}{ }^{-}\right)$species $(5,22,23)$. The formation of Cys106- $\mathrm{SO}_{2}{ }^{-}$has been proposed as one of several mechanisms that allow DJ-1 to act as a sensor of cellular redox state and to activate cytoprotective responses through the PTEN/Akt $(24)$ and ASK1 $(20,25)$ signaling pathways as well as by altering pathological protein aggregates (26-28). Other activities proposed for DJ-1, include protease $(29,30)$, esterase (31), chaperone $(32,33)$, transnitrosylase (34) and an RNA binding protein $(35,36)$. Very recently, DJ-1 was shown to prevent protein damage by derivatives of 1,3 , bisphosphoglycerate (37). Despite years of intensive study motivated by its biomedical importance, the molecular activities of DJ-1 that are responsible for its role in cell survival remain incompletely understood.

It has long been suspected that DJ-1 may possess an enzymatic activity. Cys 106 has a low $\mathrm{pK}_{\mathrm{a}}$ value of 5.4 and makes a hydrogen bond with a conserved protonated glutamic acid residue (Glu18) (38), which are features suggestive of an enzyme active site. These residues are conserved in the large DJ-1/Pfpl superfamily (39), which contains wellestablished enzymes such as archaeal Pfpl proteases $(40,41)$, isocyanide hydratases $(42-$ 44), and the Hsp31 family of glutathione-independent glyoxalases (45). In all of these enzymes, the conserved cysteine residue is a catalytic nucleophile and the protonated glutamic/aspartic acid is a probable general acid/general base. In contrast to these validated enzymes, most proposed enzymatic functions of human DJ-1 have been controversial and confounded by weak apparent activities and variable assay conditions between studies $(29,30,46,47)$.

Considerable interest has been generated by reports that human DJ-1 is a glutathione-independent glyoxalase that converts glyoxal to glycolate and methylglyoxal (MG) to L-lactate (48-51). In addition, DJ-1 has been reported to be a deglycase that repairs early glycation adducts that MG forms with DNA, RNA, small molecule thiols, and proteins (52-58). Both of these activities could protect cells by detoxifying reactive $\alpha$ ketoaldehydes produced by metabolism, but in distinct ways. A glyoxalase removes MG directly, while a deglycase acts on glycated substrates and repairs primary damage, indirectly removing MG by repairing its initial adducts. The glyoxalase activity of DJ-1 has been widely reproduced but its reported $k_{\text {cat }}$ is $\sim 10^{4}-10^{5}$ lower than the primary glutathione-dependent glyoxalase Glo1 $(59,60)$. DJ-1's deglycase activity has been controversial, and a recent study suggests that deglycation may be a secondary effect of DJ-1 acting on MG that is in rapid equilibrium with reversible MG adducts (61). Some reports indicate that $\mathrm{DJ}$-1-mediated deglycation is important for repairing certain proteins $(54,55,57,58,62)$, while others have indicated that DJ-1 has negligible effect on total cellular glycation burden $(61,63)$ and does not deglycate disease-relevant proteins such as $\alpha$-synuclein (26). In addition, several reports indicate that DJ-1 has no effect on cell viability under glycation stress in systems ranging from cultured human cells to yeast 
$(51,61,63,64)$. Therefore, both the true substrate and physiological relevance of DJ-1's anti-glycation action are debated (65).

Given the importance of DJ-1 in the etiology of several diseases, it is important to determine if a glyoxalase/deglycase activity is a major contributor to DJ-1 cytoprotection. If true, such an activity would have wide-reaching ramifications for the molecular etiology of several diseases. For example, a primary glyoxalase/deglycase activity for DJ-1 implies that reactive dicarbonyl species play a key role in the etiology of parkinsonism, as somatic DJ-1 deficiency invariably results in Parkinson's disease in humans (4). A dominant glyoxalase/deglycase model for DJ-1 cytoprotection also implies that cells possessing enhanced ability to detoxify dicarbonyls are prone to neoplastic transformation, as DJ-1 is an oncogene and its levels are elevated in multiple cancers (14). Because even low levels of glycation can cause cellular dysfunction (66), quantitative methods for measuring macromolecular glycation such as isotope dilution mass spectrometry are needed to accurately evaluate the potential influence of DJ-1 on cellular glycation burden.

In this work, we use in vitro assays to show that DJ-1 cannot deglycate irreversible adducts of $M G$ and guanine but can deglycate reversible adducts by an indirect mechanism. Steady-state enzyme kinetics using purified MG and reversible hemithioacetal substrates support a prior proposal that DJ-1's apparent deglycase activity is due to its glyoxalase activity acting on free MG. Our kinetic constants are in reasonable agreement with those recently reported by Andreeva et al. (61) and confirm that DJ-1's in vitro glyoxalase activity is many orders of magnitude lower than that of glyoxalase I (Glo1). Kinetic modeling demonstrates that the glyoxalase activity of DJ-1 is sufficient to explain the apparent deglycation kinetics. We use quantitative isotope-dilution mass spectrometry to show that DJ-1 measurably reduces the total DNA, RNA, and protein glycation burden in various neuronal cell lines and mouse brain, although the effect size is small. Cell survival in MG stress is unaffected by DJ-1 status, suggesting that DJ-1 plays a minor role in glycation defense.

\section{Results}

$D J-1$ deglycates only reversible guanine-MG adducts

DJ-1 and its homologs have been reported to deglycate a range of MG adducts including lysine residues in proteins (55) and guanine bases in DNA and RNA (54) (Fig. 1A). While the role of DJ-1 on glycated amino acids have been studied by several groups with conflicting results $(52,53,55,61,63,65)$, DJ-1's influence on nucleotide glycation has been less studied (54). We investigated the role of DJ-1 in reversing MG-modified guanine nucleosides because this reaction has been proposed to play an essential role in maintaining genomic integrity in several organisms (54). MG glycation of deoxyguanosine (dG) in DNA can form either a reversible $\mathrm{N}^{2}$-(1,2-dihydroxy-2-methyl)ethano-2'-dG (cMGdG) adduct or irreversible N2-(1-carboxyethyl)-2'-dG (CEdG) adduct via Schiff base formation and hydrolysis of an initial cMG-dG adduct (Fig. 1B). In situations where high concentrations of MG are present, CEdG can be further glycated to the stable MG-CEdG adduct (Fig. 1B). Glycation of RNA forms the corresponding guanosine adducts. The ability of recombinant DJ-1 to catalyze the deglycation of various guanine adducts was tested by mixing DJ-1 with a pre-equilibrated mixture of $M G$ and $d G$ and analyzing the resulting products by HPLC and mass spectrometry. We used MG purified by vacuum distillation (see Methods), as the purity of commercial MG is low (67). Addition of DJ-1 at the beginning of the reaction prevents formation of both reversible (cMG-dG) and irreversible (CEdG, MG-CEdG) adducts more effectively than when $M G$ and dG are incubated together for one hour before DJ-1 addition (Fig. 2A; Supplemental Fig. S1). 
This reduction in MG adducts requires the catalytic nucleophile C106, as the C106S DJ1 mutation abrogates this effect (Fig. 2B; Supplemental Fig. S1). In contrast to DJ-1's ability to prevent formation of MG adducts when added early, incubation of purified RCEdG and DJ-1 shows no change in R-CEdG chromatographic retention time on a C18 reverse phase column (67), indicating that this irreversible adduct is not a substrate for DJ-1 (Fig. 2C).

By definition, reversible adducts of $M G$ are in equilibrium with free $M G$. Our observations suggest that DJ-1 may act on free MG directly rather than on the early adducts of $M G$ and guanine. If true, this predicts that a similar reduction of only the reversible MG adducts should be observed when small molecule aldehyde scavengers are added. We confirmed this by adding the aldehyde-reactive compounds DNPH and aminoguanidine, which behave similarly to DJ-1 in reducing the levels of reversible MG adducts with dG (Supplemental Fig. S2). In aggregate, these findings are consistent with DJ-1 acting on free MG as the primary substrate, which indirectly reduces the level of only the reversible MG-nucleoside adducts.

\section{DJ-1 has weak glyoxalase and apparent deglycase activities in vitro}

Measurement of the putative deglycase activity of DJ-1 has produced variable and contradictory results, although the groups measuring this activity have used similar in vitro protocols $(38,53,55,63)$. We measured the apparent deglycase activity of DJ-1 using a well-established assay that follows the decay of the $288 \mathrm{~nm}$ absorbance of the reversible hemithioacetal formed by incubation of MG with free thiols (68)(Fig. 3A). MGhemithioacetals were formed by reaction of MG with $\mathrm{N}$-acetyl-cysteine (NAC), glutathione (GSH), or coenzyme A (CoA) (see Methods). NAC is a standard model thiol, GSH is the most abundant small molecule thiol in the cell, and CoA has been used previously as a physiologically-relevant thiol whose glycation DJ-1 can reduce (56). Tris-containing buffers were not used to avoid previously reported buffer artifacts (63). Addition of DJ-1 reduces the concentrations of each of these three hemithioacetals with initial steady-state rates that are well-fitted using the Michaelis-Menten kinetics model (Fig. 3B,C). For the three hemithioacetal substrates, the apparent $\mathrm{k}_{\text {cat }}$ values were $\sim 0.007-0.009 \mathrm{~s}^{-1}$ and $\mathrm{K}_{\mathrm{M}}$ values were $\sim 60-150 \mu \mathrm{M}$ (Table 1 ). These activities are markedly lower than some previously reported values (55). DJ-1 apparent deglycase catalytic efficiency $\left(\mathrm{k}_{\mathrm{cat}} / \mathrm{K}_{\mathrm{M}}\right)$ values are $\sim 50-100 \mathrm{M}^{-1} \mathrm{~s}^{-1}$, approximately $1 \times 10^{5}$ fold lower than that of glyoxalase 1 acting on GSH-MG hemithioacetal as substrate $\left(1.2 \times 10^{7} \mathrm{M}^{-1} \mathrm{~s}^{-1}\right.$ for $\mathrm{E}$. coli GlxI) (69).

The reactive Cys106 residue is the presumed catalytic nucleophile in human DJ1. We confirmed that DJ-1's ability to consume MG-NAC hemithioacetal is Cys106dependent by showing that neither the C106S mutant nor the Cys106-sulfinate (C106$\mathrm{SO}_{2}{ }^{-}$) oxidized form of the protein has significant apparent deglycase activity (Fig. $3 \mathrm{C}$ ). The active site environment of Cys 106 features a protonated Glu18 residue that makes a hydrogen bond to the Cys106 thiolate (38) and was identified as catalytically important in prior reports of DJ-1 glyoxalase activity (48). Consistent with these prior reports, mutations at the nearby protonated Glu18 ablated DJ-1-mediated consumption of MGNAC hemithioacetal (Fig. 3C). Our prior structural studies showed that E18D, E18N, and wild-type DJ-1 have nearly identical crystal structures and that Glu18 mutations only slightly perturb the steric environment of Cys106 $(38,70)$, suggesting that these mutations do not eliminate DJ-1's apparent deglycation activity via major changes in protein structure. Instead, it is likely that mutations at Glu18 remove an important general acid/base in the proposed DJ-1 glyoxalase mechanism (Supplemental Fig. S3). 
Because hemithioacetals are obligatorily reversible MG adducts that cannot be converted to irreversible glycated products via the Amadori rearrangement, they always exist in equilibrium with free MG. Therefore, DJ-1's apparent deglycation activity may be due to its action on free MG, as we proposed above for guanine MG adducts and was also proposed by others for other reversible MG adducts (61). DJ-1 has an established glyoxalase activity, although estimates for its kinetic parameters have varied markedly $(48,50,55,61,63,71)$. Unlike some other glyoxalases in the DJ-1 superfamily, human DJ1 produces exclusively L-lactate as a product, permitting measurement of its full catalytic activity using an L-lactate-coupled assay $(50,71)$. We measured the rate at which DJ-1 converts MG to L-lactate in real time using L-lactate oxidase, horseradish peroxidase, and resorufrin in a coupled assay that is similar to one used previously (61)(Methods). Varying the concentration of the coupling enzymes L-lactate oxidase and horseradish peroxidase has little effect on the initial rate measurements, confirming that DJ-1's activity is ratelimiting in this coupled assay. DJ-1's glyoxalase activity is well-fitted using the MichaelisMenten model (Fig. 3D) and produces kinetic constants (Table 1) which are in reasonable agreement with the $\mathrm{k}_{\mathrm{cat}} \sim 0.02 \mathrm{~s}^{-1}$ reported by Andreeva et al. (61). DJ-1's glyoxalase $\mathrm{k}_{\text {cat }}$ is $\sim 10$-fold greater than its apparent deglycase $k_{\text {cat. }}$.

Kinetic modelling indicates that DJ-1 glyoxalase activity is sufficient to explain its apparent deglycase activity

To determine if the low apparent deglycase activity for DJ-1 could be explained by its higher glyoxalase activity, we used kinetic modeling. We simulated the DJ-1-catalyzed glyoxalase reaction using a simple Michaelis-Menten mechanism (reaction 1) coupled to hemiothioacetal production via the reaction of methylglyoxal with $\mathrm{N}$-acetylcysteine (Scheme 1).

The measured progress curve for DJ-1-mediated loss of NAC-MG hemithioacetal can be adequately modeled using a kinetic scheme that includes only a glyoxalase activity for DJ-1 and an equilibrium of free MG and MG-NAC hemithioacetal, without need for a DJ1 deglycase activity (Fig. 4A). The modeled kinetic parameters for DJ-1 glyoxalase activity also agree well with the measured glyoxalase activity progress curves of the enzyme (Fig. 4B) and produce glyoxalase $\mathrm{k}_{\mathrm{cat}}$ and $\mathrm{K}_{\mathrm{m}}$ values that agree well with the experimentally determined ones (Table 2). The ability to fit the data in Fig. 4 without needing to invoke a postulated DJ-1 deglycase activity supports the conclusion (61) that $\mathrm{DJ}-1$ is not a primary deglycase but reduces the concentrations of reversible MG adducts through its action on MG and the equilibria in Scheme 1.

\section{DJ-1 reduces total protein and nucleic acid glycation burden in cultured neuronal cells and} mice

DJ-1's contribution to reducing the overall glycation burden in cells is contentious, with some studies indicating major effects $(54,55,58)$ and others detecting no changes $(61,63)$. In these studies, protein glycation has been measured primarily using Western blotting. Western-based detection of glycated macromolecules is complicated by the need for specific antibodies against the modification of interest and the difficulty of quantifying the blots. To address these limitations, we used quantitative isotope dilution mass spectrometry with internal ${ }^{15} \mathrm{~N}_{5}-\mathrm{CEdG},{ }^{15} \mathrm{~N}_{5}-\mathrm{CEG}, \mathrm{CEL}-\mathrm{d} 4$ and Lys-d4 standards for quantifying glycated guanine in DNA, RNA and glycated lysine in proteins. Using dopaminergic M17 neuroblastoma cells, we knocked down DJ-1 using siRNA (see Methods) and observed a trend of increased CEdG, CEG, and CEL levels when DJ-1 levels are decreased, although these effects are small (Fig. 5A). 
Although M17 cells are biochemically similar to the vulnerable neurons in Parkinson's Disease, they are immortalized and thus have potential alterations in metabolism that could affect glycation. To address this, we also measured glycated products in two distinct neuronal lineages: induced pluripotent stem cell-derived forebrain neurons created from fibroblasts donated by a patient bearing a $A 111 \mathrm{~L}$ missense mutation that eliminates steady-state DJ-1 (72) and primary neurons cultured from DJ-1/- mice. In both DJ-1-deficient neuronal cultures, glycation products are slightly elevated (Fig. 5A-C), although this increase only reaches the $p<0.05$ significance threshold for CEL in M17 cells and CEG in iPSC-derived neurons (Fig. 5A,B). A similar effect is seen in overall mouse brain tissue, where DJ-1 knockout elevates all three classes of glycated products by 1-2 modified species $/ 10^{6}$ unmodified, which is statistically significant for CEG and CEL (Supplemental Fig. S4).

The glutathione-dependent glyoxalase I/II (Glol/II) system is the primary means for detoxifying MG in the cell. Because the in vitro catalytic rate of Glol is several orders of magnitude greater than that of DJ-1, it is possible that DJ-1 would make a larger contribution to glycation defense when the Glol/ll is impaired. We tested this using buthionine sulfoximine (BSO), an inhibitor of $\gamma$-glutamyl cysteine ligase, the rate-limiting enzyme in glutathione (GSH) biosynthesis (73). As GSH is a co-substrate for Glol, reduction in the GSH pool should reduce Glol activity in cells. BSO administration to M17 neuroblastoma cells markedly increases CEL levels when compared to vehicle alone, although the effect on CEG and CEdG levels are not significant. When BSO is applied to DJ-1 knockdown cells, it leads to significant increases in all three glycated metabolites (CEdG, CEG, and CEL) and this effect is again most pronounced for CEL (Fig. 6C). The enhancement of glycation when BSO is applied to DJ-1 knockdown cells suggests that Glo1's stronger glyoxalase activity dominates the cellular MG defense compared to DJ1 's weaker glyoxalase activity.

\section{DJ-1 does not protect cells against MG toxicity}

DJ-1 decreases total cellular CEdG, CEG, and CEL levels in some instances, although the absolute magnitude of this decrement is relatively small $\left(\sim 1-2\right.$ glycated products $/ 10^{5}$ unmodified). To determine if this reduction in glycation corresponds to increased cellular protection against MG toxicity by DJ-1, we measured the effect of DJ-1 on survival of both M17 neuroblastoma cells and iPSC-derived neurons in 10-10000 $\mu \mathrm{M}$ exogenously added MG. M17 cells show a clear loss of viability with an IC ${ }_{50}$ of $809.2 \mu M$ MG, but DJ-1 siRNA knockdown has no effect on cell survival (Fig. 7). Sensitization to MG, resulting in a decrease of $\mathrm{IC}_{50}$, would be expected if $\mathrm{DJ}-1$ made a significant contribution to cellular viability during MG challenge of these cells. Neurons derived from iPSCs show no loss of viability across a 10-1000 $\mu \mathrm{M}$ MG range, and the inactivating A111L DJ-1 mutation does not sensitize them to MG (Fig. 7). These negative results are consistent with prior reports that loss of DJ-1 has no effect on MG sensitivity in Drosophila and HEK293 cells $(61,63)$.

\section{Discussion}

DJ-1 defends multiple types of cells against oxidative stress and mitochondrial damage. One model of DJ-1-mediated cytoprotection is that it is a redox-responsive protein that uses cysteine oxidation to sense changes in redox homeostasis and enhances cell survival through the PTEN/Akt $(74)$, Nrf2 $(16,75)$, and ASK1 $(20,25)$ signaling pathways. However, DJ-1 has more recently been reported to have Cys106-dependent glyoxalase and deglycase activities, indicating that the protein may also play important roles in defense against reactive carbonyl species such as MG. DJ-1's glyoxalase activity is 
widely corroborated, although it is significantly less efficient than Glo1 and there is considerable disagreement regarding DJ-1's kinetic constants. The deglycase activity for DJ-1 is more controversial, with some groups reporting that it is either an artifact (63) or an apparent activity of DJ-1 acting on methylglyoxal (61), while others report that deglycation is the most important activity of DJ-1 $(54,55)$.

Our results help resolve this dispute, as we find that DJ-1 is a weak glyoxalase with a $\mathrm{k}_{\text {cat }} \sim 0.07 \mathrm{~s}^{-1}$. This is $\sim 100 \mathrm{x}$ lower than the average enzyme $\mathrm{k}_{\text {cat }}$ value (76), but is still 10x higher than the maximal rate of DJ-1's apparent deglycase activity. There has been disagreement in the literature about kinetic constants for DJ-1's glyoxalase activity (65), and we note that our results agree reasonably well with those of Andreeva et al. measured in the same buffer (61). We observe that DJ-1 can only reduce the levels of freely reversible MG adducts in vitro, and our kinetic modeling shows that DJ-1's glyoxalase activity is sufficient to explain its this apparent activity on MG adducts. Here again, these new quantitative kinetic modeling results support the conclusions of Andreeva at al. (61) that the apparent deglycase activity of DJ-1 is likely due to its action on free MG regardless of the reversibly glycated species: aminocarbinol, hemithioacetal, cyclic dihydroimidazolone, or others. This conclusion contradicts several reports from the Richarme group (52-55) but is chemically sensible, as there is no clear mechanism by which a cysteine nucleophile-dependent enzyme could deglycate these diverse species, all of which lack a plausible electrophilic center for Cys106 thiolate attack. In addition, we find that both the E18N and E18D mutants eliminate DJ-1's ability to revert reversibly glycated species, consistent with some prior reports $(48,56)$ and demonstrating that Glu18 is catalytically essential for DJ-1 glyoxalase activity. Considering these results in the context of the DJ-1 crystal structure, we propose a mechanism where the protonated Glu18 is the general acid that protonates the oxyanion formed upon Cys106 attack at the electrophilic aldehyde carbon atom of MG (Supplemental Fig. S3).

Prior studies show that E18N and E18Q DJ-1 can protect cells from mitochondrial damage induced by rotenone, preserve normal mitochondrial morphology (70), and are functional in other assays of DJ-1 activity $(21,25)$. These results indicate that aspects of DJ-1 cytoprotection related to oxidative stress response and mitochondrial dysfunction are not explained by DJ-1's glyoxalase activity. Furthermore, any cytoprotective enzymatic activity that requires Cys 106 as the catalytic nucleophile will be abrogated by oxidation of Cys106 that occurs during oxidative stress, suggesting that DJ-1's known enzymatic and redox-sensing protective mechanisms are orthogonal and require different cellular pools of the protein.

The low catalytic efficiency of DJ-1's glyoxalase activity $\left(k_{\text {cat }} / K_{M}=210 M^{-1} s^{-1}\right)$ raises questions about its physiological relevance, as it is much lower than the $\sim 10^{7} \mathrm{M}^{-1} \mathrm{~s}^{-1} \mathrm{k}_{\text {cat }} / \mathrm{K}_{\mathrm{M}}$ of Glo1 $(69,77)$. Glo1, a highly conserved and widely expressed enzyme that converts the MG-glutathione hemithioacetal to S-lactoylglutathione, is the dominant mechanism of MG detoxification in most cells. It seems implausible that DJ-1 could contribute significantly to the cellular defense against MG against a background of more catalytically proficient Glo1 unless Glo1 activity is diminished by glutathione depletion or other mechanisms. Despite these considerations, we find using sensitive and quantitative isotope dilution mass spectrometry that the absence of DJ-1 results in small elevations in neuronal CEdG, CEG, and CEL, three surrogate biomarkers for MG reaction with DNA, RNA, and protein, respectively. These elevated levels are found in immortalized M17 neuroblastoma cells, iPSC-derived neurons, primary mouse neurons, and whole mouse brain, establishing that this is observed across multiple neuronal types. Moreover, the effect is observed both in 
vivo and under standard cell culture conditions without external (and unphysiological) administration of bolus MG. Although the effect size is modest, it is nonetheless surprising given the low catalytic activity of DJ-1. We offer two speculative hypotheses that may explain this result. First, DJ-1 may have substantially greater glyoxalase activity in the cell than observed in vitro using recombinant protein, perhaps owing to the presence of yetunknown modifications or regulators in the cell that enhance its activity. This explanation may seem contrived, however this effect has been observed for the related Hsp31 glyoxalase in Saccharomyces cerevisiae, although the cause of endogenous Hsp31's enhanced activity is unknown (78). Further supporting the sensitivity of DJ-1's glyoxalase activity to the details of the solution reaction environment, the in vitro DJ-1 glyoxalase activity is markedly higher in phosphate buffer than in PBS (79). Second, it is possible that DJ-1's glyoxalase activity is not directly responsible for its ability to reduce cellular glycation burden. In this model, DJ-1 would enhance the activities of other pathways that are more effective at reducing steady-state levels of MG. This model could be tested using mutations such as $\mathrm{E} 18 \mathrm{~N}$ that eliminate DJ-1 glyoxalase activity but preserve its protective activity against oxidative and mitochondrial damage stressors and warrant further investigation.

DJ-1 does not improve cellular viability against MG toxicity in our experiments, supporting some prior reports $(61,63)$ while contradicting others $(48,55)$. It is possible that DJ-1's modest ability to reduce glycation may be more important for survival of certain types of cells, although the studies reporting negative results used human and mouse neurons (this work), HEK293 cells (61), Drosophila (63), S. cerevisiae (64), and S. pombe (51). The yeast studies are informative, as they show that overexpressed human or $S$. pombe DJ-1 does not rescue the greatly increased sensitivity to exogenous MG that results from knockout of Glo1. By contrast, these same studies showed that Hsp31 proteins, which are more active glutathione-independent glyoxalases in the DJ-1 superfamily, can rescue viability of Glo1-deficient yeasts $(51,64)$. Hsp31 has a $k_{\text {cat }} / K_{M}$ for MG of $\sim 10^{3}-10^{4} \mathrm{M}^{-1} \mathrm{~s}^{-1}$, which is 10-100-fold higher than DJ-1 but still 1000-10000-fold lower than Glo1. Therefore, the ability of Hsp31 to rescue MG sensitivity in $\triangle$ GLO1 yeast shows that these complementation experiments are sensitive enough to detect glyoxalase activities that are several orders of magnitude lower than Glo1. In light of our present results and prior independent negative reports, DJ-1's glyoxalase activity does not appear to be physiologically relevant for overall cell viability when challenged with exogenous MG. Our results do not directly address a potential role for DJ-1 in protecting specific proteins from glycation, which has been reported for histones $(57,62)$. It is speculatively possible that DJ-1's weak glyoxalase activity may be especially important for sensitive proteins or specific cellular compartments that are not addressed in this global study of cellular glycation.

Very recently, DJ-1 and its close homologs were shown to strongly protect proteins and metabolites against glycerate and phosphoglycerate modifications (37). In that study, DJ-1 was proposed to use Cys106 to open a reactive cyclic 1,3 phosphoglycerate metabolite that may be spontaneously formed from 1,3 bisphosphoglycerate (i.e. DJ-1 is a cyclic 1,3 phosphoglycerate phosphodiesterase). This enzymatic activity is difficult to directly assay owing to the instability of the presumptive substrate so we did not investigate it in this study. However, we note that such an activity may provide a functional explanation for the tendency of the Arg28/Arg48 motif near the DJ-1 active site to bind tetrahedral anions (38). The presence of this anion-binding di-arginine motif is more consistent with DJ-1 acting on a phosphate-containing substrate than with MG being its primary substrate. As we discuss above for DJ-1 glyoxalase activity, mutation of Glu18 
could be used to interrogate the importance of a DJ-1 cyclic 1,3 phosphoglycerate phosphodiesterase activity relative to other potential roles of oxidized isoforms of the protein, which we predict would be affected differently by E18N/D/Q mutations. Finally, it is intriguing (though possibly coincidental) that both glyoxalase and cyclic 1,3 phosphoglycerate phosphodiesterase activities act on triose phosphate-derived metabolites resulting from glycolysis, which is restricted to the cytosol in eukaryotic cells.

\section{Material and Methods}

Protein Expression and Purification

The gene for human DJ-1 was cloned between the Ndel and Xhol sites of Escherichia coli expression vector $\mathrm{pET} 15 \mathrm{~b}$ and the $\mathrm{C} 106 \mathrm{~S}, \mathrm{E} 18 \mathrm{D}$, and $\mathrm{E} 18 \mathrm{~N}$ mutants were generated by site-directed mutagenesis and previously described (38). The constructs were transformed into E. coli BL21 (DE3) cells and protein expression and purification were performed as described previously (80). Briefly, the protein was purified by $\mathrm{Ni}^{2+}$ metal affinity chromatography, the hexahistitdine tag was removed from recombinant DJ-1 by thrombin cleavage, and the protein was passed through $\mathrm{Hi}-\mathrm{Q}$ anion exchange column (Bio-Rad Laboratories, Hercules, CA, USA) to remove minor nucleic acid contamination. Thrombin was removed using benazamidine-sepharose 4 resin (Cytiva catalog number 17512310). All proteins ran as a single band on overloaded Coomassie-stained SDSPAGE and were concentrated using a 10-kDa cutoff centrifugal concentrator (Millipore) to $20 \mathrm{mg} / \mathrm{ml}$ in storage buffer (25 mM HEPES pH 7.5, $100 \mathrm{mM} \mathrm{KCl}, 2-5 \mathrm{mM}$ DTT). DJ-1 concentration was determined by the absorbance at $280 \mathrm{~nm}$ using a calculated extinction coefficient at $280 \mathrm{~nm}$ of $4400 \mathrm{M}^{-1} \mathrm{~cm}^{-1}$. The purified protein in storage buffer was snapfrozen in liquid nitrogen and stored at $-80^{\circ} \mathrm{C}$.

DJ-1 was oxidized at Cys106 as described previously (80). Briefly, $0.25 \mathrm{mM}$ DJ1 in storage buffer was dialyzed against PBS $(\mathrm{pH} 7.4)$, followed by addition of $\mathrm{H}_{2} \mathrm{O}_{2}$ (Invitrogen) to a final concentration of $1.75 \mathrm{mM}$ (i.e. a $7: 1$ molar ratio of $\mathrm{H}_{2} \mathrm{O}_{2}$ to $\mathrm{DJ}-1$ monomer) and the mixture was incubated on ice for 45 min. Unreacted $\mathrm{H}_{2} \mathrm{O}_{2}$ was removed by Bio-Gel P-6 desalting resin. Prior work has shown that this procedure selectively oxidizes Cys106 in human DJ-1 (27,70,80). Electrospray mass spectrometry using an Agilent 1200 LC system (Agilent Technologies, Santa Clara, CA, USA) with the electrospray ionization (ESI) source of a Bruker Solarix - 70 hybrid Fourier transform mass spectrometer (Redox Biology Center (RBC) Mass Spectrometry Core Facility, the University of Nebraska-Lincoln) confirmed that DJ-1 was purified in the fully reduced form and that $\mathrm{H}_{2} \mathrm{O}_{2}$ oxidation increased the intact mass of DJ-1 by 32 a.m.u, consistent with Cys106- $\mathrm{SO}_{2}{ }^{-}$formation. In addition, preparations of DJ-1 were tested for proper folding by crystallization and X-ray crystal structure analysis. All preparations of the protein crystallize readily and produce crystal structures that are essentially identical $\left(C_{\alpha}\right.$ RMSD $\sim 0.05 \AA$ ) to prior human DJ-1 structures deposited in the Protein Data Bank (e.g. accession code 1P5F, 5SY6).

In vitro deglycase and glyoxalase assays

Commercial methylglyoxal (MG) is known to be contaminated with several species that may interfere with kinetic measurements. Therefore, MG was purified from pyruvaldehyde-1-dimethyl acetal as previously reported (67) and stored frozen in small aliquots at $-80{ }^{\circ} \mathrm{C}$ until needed. $10 \mathrm{mM} \mathrm{N}$-acetyl-cysteine (Alfa Aesar catalog number A15409), glutathione (Acros Organics catalog number 120000250), or coenzyme A (Affymetrix catalog number 13787) were mixed with $10 \mathrm{mM}$ of freshly thawed methyglyoxal 
and incubated at $25^{\circ} \mathrm{C}$ until the absorption at $288 \mathrm{~nm}$ was stable ( 1 hour), indicating that hemithioacetal formation was at equilibrium.

DJ-1 was dialyzed against degased PBS buffer (137 mM NaCl, $2.7 \mathrm{mM} \mathrm{KCl,} 10$ $\mathrm{mM} \mathrm{Na} \mathrm{HPO}_{4}, 1.8 \mathrm{mM} \mathrm{KH}_{2} \mathrm{PO}_{4} \mathrm{pH} 7.4$ ) immediately before the kinetic measurements. This buffer was chosen because it was used by both Richarme et al. (55) and Pfaff et al. (63), thereby facilitating direct comparison of our results to prior reports. We note that DJ1 is reported to be less active in PBS than in other buffers (79), which might be relevant for reconciling the low glyoxalase activity of DJ-1 in vitro with its observed effects in vivo. Andreeva et al. recently reported new equilibrium constants for the formation of MGhemithioacetals, which are substantially lower than prior values (61). Therefore, not all of the added $M G$ and thiol react to form the hemithioacetal species (79). Initial concentrations of the NAC-MG and GSH-MG hemithioacetal substrates were determined using the updated molar extinction coefficient of $300 \mathrm{M}^{-1} \mathrm{~cm}^{-1}$ and $250 \mathrm{M}^{-1} \mathrm{~cm}^{-1}$, respectively (61). The CoA-MG hemithioacetal molar extinction coefficient has not been reported, so it was presumed to be the same as GSH-MG. The reaction was initiated by the addition of DJ-1 (wild-type, Cys106-SO ${ }_{2}^{-}, \mathrm{C} 106 \mathrm{~S}, \mathrm{E} 18 \mathrm{~N}$ and E18D) to $10 \mu \mathrm{M}$ final concentration. The $\mathrm{A}_{288}$ was measured for six minutes at $25{ }^{\circ} \mathrm{C}$ using a Cary50 UV-visible spectrophotometer (Varian, Palo Alto, CA, USA) and always showed a linear decrease over this timeframe. The slope of the best-fit line to the measured decrease in $A_{288}$ signal was used to calculate the initial rate $\left(\mathrm{V}_{0}\right)$ of hemithioacetal consumption. Because the hemithioacetal spontaneously degrades in aqueous solutions, a buffer-alone baseline was measured in order to correct for non-catalytic loss of $288 \mathrm{~nm}$ signal. The difference between the buffer-alone and buffer-enzyme curve was taken to reflect DJ-1 activity. All measurements were repeated at least three times and average values with associated standard deviations are reported.

DJ-1 glyoxalase activity was measured using a coupled assay of L-lactate oxidase and Amplex Red/horseradish peroxidase (HRP). In this assay, DJ-1 glyoxalase activity generates L-lactate (71), which is oxidized by L-Lactate oxidase and molecular oxygen to generate pyruvate and $\mathrm{H}_{2} \mathrm{O}_{2}$. The liberated $\mathrm{H}_{2} \mathrm{O}_{2}$ and Amplex Red are co-substrates for $\mathrm{HRP}$, generating fluorescent resorufin. The rate of $\mathrm{H}_{2} \mathrm{O}_{2}$ generation was monitored using the Amplex Red Hydrogen Peroxide/Peroxidase Assay Kit (Invitrogen). Various concentrations of purified MG were added to the Amplex Red working solution (including Amplex Red reagent and horseradish peroxidase (HRP)), 0.4 units of L-lactate oxidase (Sigma, catalog number L9795), in reaction buffer (50 mM sodium phosphate, $\mathrm{pH} 7.4$, as provided in the kit) at $25^{\circ} \mathrm{C}$. The reaction was initiated by adding human DJ-1 to a final concentration $0.1 \mu \mathrm{M} . \mathrm{H}_{2} \mathrm{O}_{2}$ generation was measured for 5 minutes using a Cary Eclipse spectrofluorimeter (Varian, Palo Alto, CA, USA) with an excitation wavelength at $540 \mathrm{~nm}$ and emission wavelength of $590 \mathrm{~nm}$. The measured rates are linear in DJ-1 concentration, confirming that the coupling enzymes were not rate-limiting. All reaction rates were linear over this timeframe and the slope of the best-fit line was converted to $\mathrm{H}_{2} \mathrm{O}_{2}$ concentration using a standard curve generated with known concentrations of $\mathrm{H}_{2} \mathrm{O}_{2}$.

\section{DJ-1 glyoxalase/deglycase kinetic simulations and data fitting}

Data were fit using KinTek global kinetic explorer software (version 10.1.8.beta). The KinTek software simulates reactions by automatically deriving the corresponding system of rate equations, solving them using numerical integration, and fitting kinetic data using non-linear least squares (81). Initial conditions were set using the experimental values. Loss of MG-NAC hemithioacetal was simulated using a molar extinction value at $288 \mathrm{~nm}$ of $300 \mathrm{M}^{-1} \mathrm{~cm}^{-1}$, along with the mechanism and rate constants described in Table 2 using 
experimental conditions described above. The simulation recapitulated the experimental protocol, simulating initial hemoithioacetal formation by mixing $10 \mathrm{mM}$ of MG and NAC for $2 \mathrm{hrs}$, diluted as indicated in Figure 4, and mixed with DJ-1 (10 $\mu \mathrm{M})$ for 2 minutes prior to data collection at $288 \mathrm{~nm}$. The equilibrium constant for reaction 2 was fixed using a previously determined value of $500 \mathrm{M}^{-1}(61)$. The rate constants for reaction 1 and 2 were adjusted to globally fit all progress curve data, where best-fit rate constants can be found in Table 2. Confidence intervals for parameters were obtained by the KinTek software (82) by finding rates constants that produce a 0.83 relative error or chi squared ratio $\left(\frac{\chi_{\text {best }}^{2}}{\chi_{i}^{2}}\right)$ to the best-fit found in Table 2. DJ-1-catalyzed L-lactate formation was monitored through a coupled lactate oxidase and amplex red assay as described above. Lactate oxidation and subsequent formation of $\mathrm{H}_{2} \mathrm{O}_{2}$ to produce fluorescence were made non-rate limiting in the simulation by increasing the rate constant for formation of fluorescent product to an arbitrary value of $3.9 \times 10^{4} \mathrm{~min}^{-1}$. Simulation of the fluorescent product (Figure 4B) using a linear fluorescent coefficient was based on a $\mathrm{H}_{2} \mathrm{O}_{2}$ Amplex Red standard curve but then optimized to $3.63 \times 10^{7} \mathrm{M}^{-1}$ in the fitting.

\section{Culture of M17 neuroblastoma cell lines}

Clonal M17 cell lines stably expressing different control and DJ-1 shRNA sequences were manufactured as described previously (35). Cells were cultured to confluency in Opti-MEM (ThermoFisher, catalog number 31985088) + 10\% fetal bovine serum (Gemini BioProducts, catalog number 900-108) $+5 \mu \mathrm{g} / \mathrm{mL}$ Blasticidin (ThermoFisher, catalog number A1113903). For treatment experiments, control and DJ-1 shRNA M17 cells $(n=4)$ were treated with either regular media or buthionine sulfoximine $(43 \mathrm{mM})$ for $8 \mathrm{hr}$. Following treatment, cells were processed for DNA, RNA, and protein isolation (see below). Treatment concentrations used were the $\mathrm{IC}_{50}$ determined by toxicity following $24 \mathrm{hr}$ treatment exposure using $0,0.1,1,10$ and $100 \mathrm{mM}$ for buthionine sulfoximine (83).

\section{Murine primary neuronal cultures}

Cortical neuron-enriched primary cultures were prepared from wildtype and DJ-1 knockout mouse pups between postnatal days 1-2 and cultured in Basal medium eagle $(+1 \times \mathrm{B}-27$ minus vitamin $\mathrm{A}, 1 \mathrm{x}$ N2 supplement, $0.5 \mathrm{mM}$ glutamine, $45 \%$ glucose, $1 \mathrm{x}$ PenicillinStreptomycin).

\section{Monolayer forebrain neuronal differentiation from human iPSC}

A commercial iPSC line (ThermoFisher, catalog number A18945) and the DJ-1 knockout iPSC line HT-188 (72) were grown on a layer of MEFs (MTI-GlobalStem, catalog number GSC-6201G) in Essential 8TM media (ThermoFisher, catalog number A1517001) until $100 \%$ confluent. Confluent cells were transitioned to N3 media (50\% DMEM/F12, 50\% Neurobasal with 1x Penicillin-Streptomycin, $0.5 x$ B-27 minus vitamin $A, 0.5 x \quad N 2$ supplement, 1x Glutamax, 1x NEAA, $0.055 \mathrm{mM} 2$-mercaptoethanol and 1 $\mathrm{\mu g} / \mathrm{ml}$ Insulin) plus $1.5 \mu \mathrm{M}$ Dorsomorphin (Tocris Bioscience) and $10 \mu \mathrm{M}$ SB431542 (Stemgent) daily for 11 days. On days 12-15, cells were fed each day with N3 without Dorsomorphin and SB431542. On days 16-20, N3 was supplemented with $0.05 \mu \mathrm{M}$ retinoic acid. On day 20, cells were split 1:2 with trypsin and seeded with ROCK inhibitor onto Poly-L-ornithine (Sigma), fibronectin and laminin coated plates. From days 21 to time of extraction, cells were fed with N4 media (same as N3 plus $0.05 \mu \mathrm{M}$ Retinoic acid, $2 \mathrm{ng} / \mathrm{ml}$ BDNF and 2 ng/ml GDNF).

\section{DJ-1 knockout mice}


Male and female WT $(n=5)$ and DJ-1 knockout $(n=6)$ mice (C57BL/6) were given access to food and water ad libitum and housed in a facility with 12-h light/dark cycles. Mice were sacrificed between $20-22$ months of age and brains were flash frozen and stored at $-80^{\circ} \mathrm{C}$. Brains were homogenized into a frozen powder using liquid nitrogen and separated for DNA, RNA, and protein extractions.

\section{RNA extraction for glycation analysis}

All cell lines were seeded at $\sim 1 \times 10^{6}$ per 12 well with $n=4$ wells used for RNA, DNA, or protein extraction. Cells were lysed using $0.4 \mathrm{~mL}$ TRIzol ${ }^{\mathrm{TM}}$ reagent (ThermoFisher, catalog number 15596026) and $0.08 \mathrm{~mL}$ chloroform. Following centrifugation for 15 minutes at $4^{\circ} \mathrm{C}$ at $12,000 \mathrm{xg}$, the top aqueous layer was transferred to a new Eppendorf tube. RNA was precipitated with the addition of $0.2 \mathrm{~mL}$ isopropanol followed by centrifugation for 10 minutes. RNA pellet was washed with $0.4 \mathrm{~mL} 75 \%$ ethanol and centrifuged for 5 minutes at 7,500xg. Supernatant was discarded and pellet was air dried then resuspended in $20 \mu \mathrm{L}$ RNase-free water. To complete solubilizing the RNA, incubation in water bath at $55^{\circ} \mathrm{C}$ occurred for 15 minutes. RNA from brain samples were processed using the same protocol. RNA concentration was quantified using spectrophotometer.

\section{DNA extraction for glycation analysis}

Cells were rinsed, scraped, and pelleted using sterile PBS. Cells were resuspended in equal volumes PBS and phenol:chloroform:isoamyl (25:24:1) and spun for 5 minutes at $16,000 x g$. Top aqueous layer was transferred to a new Eppendorf tube. DNA was precipitated by adding $0.5 x$ volume of $7.5 \mathrm{M}$ ammonium acetate and 3x volume of $100 \%$ ethanol then stored at $-20^{\circ} \mathrm{C}$ overnight. DNA was pelleted by centrifugation for 30 minutes at $4^{\circ} \mathrm{C}$ at $16,000 \mathrm{xg}$. Supernatant was removed and pellet was washed with $70 \%$ ethanol. Following centrifugation, supernatant was removed, pellet was air dried and resuspended in $100 \mu \mathrm{L}$ autoclaved water. DNA from brain samples was isolated using the DNeasy Blood and Tissue kit (Qiagen, 69504). DNA concentration was quantified using spectrophotometer.

\section{Protein extraction for glycation analysis}

Cells were scraped and lysed with lysis buffer ( $1 \mathrm{x}$ cell lysis buffer (Cell Signaling Technology, 9803), 1x protease inhibitor (Sigma, 4693159001), and 1x phosphatase inhibitor (ThermoFisher, 78427)). Lysed cells were set to rotate for 30 minutes at $4^{\circ} \mathrm{C}$ then spun at $>20,000 \mathrm{xg}$ for 8 minutes at $4^{\circ} \mathrm{C}$. Supernatant was transferred to a new Eppendorf tube and protein concentration measured using the Pierce ${ }^{\mathrm{TM}} 660 \mathrm{~nm}$ protein assay. Protein from brain samples were extracted using a similar protocol.

HPLC analysis of MG reaction with $d G$ in the presence of $D J-1$

$M G$ was synthesized as previously described (84) and reacted $(5 \mathrm{mM})$ with dG $(0.5 \mathrm{mM})$ in $50 \mathrm{mM}$ sodium phosphate, $\mathrm{pH} 7.5$ for $1 \mathrm{hr}$ at $37^{\circ} \mathrm{C}$. DJ-1 $(5 \mu \mathrm{M})$ was added for an additional $24 \mathrm{hr}$. Reactions were also performed in which DJ-1 was added concomitantly with MG and dG. Following incubation, reactions were analyzed on an Agilent 1100 HPLC as previous described (67). Reactions with dinitrophenylhydrazine (DNPH) were performed by making a $10 \mathrm{mM}$ DNPH stock in $2.5 \mathrm{M} \mathrm{HCl}$ with dilution to $5 \mathrm{mM}$ in $\mathrm{H}_{2} \mathrm{O}$. DNPH ( $5 \mathrm{mM}$ ) was added to reactions for 15 minutes followed by addition of $2.5 \mathrm{M} \mathrm{NaOH}$ prior to injection on HPLC. Absorbance from 210-510 nm was monitored.

Mass Spectrometric analysis of CEdG, CEG, and CEL from WT and DJ-1 KD cells 
Standards were synthesized as previously described (67). CEL-d4 standard was obtained from Santa Cruz Biotechnology (sc219424). CEL was obtained from Abcam (ab145095). DNA and RNA was isolated as described above, spiked with $5 \mathrm{ng} / \mathrm{mL}^{15} \mathrm{~N}_{5}-\mathrm{CEdG}$ or ${ }^{15} \mathrm{~N}_{5^{-}}$ CEG and digested as previously described (84). Protein was isolated as described above and up to $50 \mu \mathrm{g}$ of protein per sample was spiked with $5 \mathrm{ng} / \mathrm{mL}$ of CEL-d4 and Lys-d4. Samples was incubated in $6 \mathrm{M} \mathrm{HCl}$ for $18 \mathrm{hr}$ at $110^{\circ} \mathrm{C}$ and then dried under nitrogen with incubation at $80{ }^{\circ} \mathrm{C}$, resuspended in $50 \mu \mathrm{L} 0.5 \% \mathrm{HFBA}$, and then analyzed using LCMS/MS. CEdG and CEG were analyzed by injection onto an Agilent Zorbax SB-C18 column $(2.1 \times 50 \mathrm{~mm}, 1.8 \mu \mathrm{m})$ with mobile phases $\mathrm{A}: \mathrm{H}_{2} \mathrm{O}+0.1 \%$ formic acid and $\mathrm{B}$ : acetonitrile $+0.1 \%$ formic acid at $0.4 \mathrm{~mL} / \mathrm{min}$. The following gradient was used to separate analytes: $3 \%-10 \%$ B from 0-4.5 min, 10\%-97\% B from 4.5-4.8 min, $97 \%$ B from 4.8 to 5.2 $\mathrm{min}, 97 \%$ to $3 \% \mathrm{~B}$ from 5.2 to $5.7 \mathrm{~min}$. CEL was analyzed on this same column with an isocratic flow of $10 \% \mathrm{ACN}+0.1 \%$ formic acid at $0.2 \mathrm{~mL} / \mathrm{min}$. The following mass transitions were monitored: CEdG $\mathrm{m} / \mathrm{z} 340$ to $224,{ }^{15} \mathrm{~N}_{5}$-CEdG $\mathrm{m} / \mathrm{z} 345$ to 229 , CEG $\mathrm{m} / \mathrm{z}$ 356 to 224 , and ${ }^{15} \mathrm{~N}_{5}$-CEG $\mathrm{m} / \mathrm{z} 361$ to 229 . CEL $\mathrm{m} / \mathrm{z} 219$ to 130 CEL-d4 m/z 223-134, Lys $\mathrm{m} / \mathrm{z} 147-84$, and Lys-d4 $\mathrm{m} / \mathrm{z} 151$ to 88 . Analytes were quantified by fitting to a standard curve and the normalization to dG or guanosine (measured as described below), or lysine, as appropriate.

\section{HPLC quantitation of $d G$ and Guanosine}

Following mass spectrometric quantitation of CEdG and CEG, dG and guanosine were quantified on an Agilent $1100 \mathrm{HPLC}$ using an Atlantis T3 column $4.6 \times 150 \mathrm{~mm}, 5 \mu \mathrm{m}$. The mobile phases were $\mathrm{A}: \mathrm{H}_{2} \mathrm{O}+0.1 \%$ formic acid and $\mathrm{B}$ : $\mathrm{ACN}+0.1 \%$ formic acid with a flow rate of $0.426 \mathrm{~mL} / \mathrm{min}$. The following gradient was used: $0-9 \% \mathrm{~B}, 0-20 \mathrm{~min} ; 9-9.5 \%$ B, 20-55 min; 9.5\%-90\% B, 55-60 min and hold $60-70 \mathrm{~min} .90 \%-0 \% \mathrm{~B}, 70-75 \mathrm{~min} ; 0 \% \mathrm{~B}$, $75-80 \mathrm{~min}$. The area under the curve was manually integrated and then fit to a standard curve to determine dG or $\mathrm{G}$ concentration.

Statistical analysis

Comparisons between various groups were performed using two-way ANOVA with Tukey's multiple comparisons test and an alpha value of 0.05 as implemented in Prism 9.3.0 (GraphPad software).

Acknowledgements/Conflict of Interest Disclosure: We thank Dr. Javier Seravalli (Redox Biology Center Mass Spectrometry Core Facility, University of Nebraska) for assistance with mass spectrometry of recombinant DJ-1. This research was supported in part by the Intramural research Program of the National Institutes of Health $(\mathrm{NIH}$; Bethesda, MD, USA), National institute on Aging. MAW acknowledges support from $\mathrm{NIH}$ R01GM139978, JT R01CA176611. Work performed in the Mass Spectrometry Shared Resource at City of Hope is supported by the National Cancer Institute of the National Institute of Health under award number P30 CA033572. The authors declare no conflicts of interest that would affect the objectivity of this study.

\section{References}

1. Bandyopadhyay, S., and Cookson, M. R. (2004) Evolutionary and functional relationships within the DJ1 superfamily. BMC Evol Biol 4, 6

2. Lucas, J. I., and Marin, I. (2007) A new evolutionary paradigm for the Parkinson disease gene DJ-1. Mol Biol Evol 24, 551-561

3. Wilson, M. A., Ringe, D., and Petsko, G. A. (2005) The atomic resolution crystal structure of the YajL (ThiJ) protein from Escherichia coli: a close prokaryotic homologue of the Parkinsonism-associated protein DJ-1. J Mol Biol 353, 678-691 
4. Bonifati, V., Rizzu, P., van Baren, M. J., Schaap, O., Breedveld, G. J., Krieger, E., Dekker, M. C., Squitieri, F., Ibanez, P., Joosse, M., van Dongen, J. W., Vanacore, N., van Swieten, J. C., Brice, A., Meco, G., van Duijn, C. M., Oostra, B. A., and Heutink, P. (2003) Mutations in the DJ-1 gene associated with autosomal recessive early-onset parkinsonism. Science 299, 256-259

5. Canet-Aviles, R. M., Wilson, M. A., Miller, D. W., Ahmad, R., McLendon, C., Bandyopadhyay, S., Baptista, M. J., Ringe, D., Petsko, G. A., and Cookson, M. R. (2004) The Parkinson's disease protein DJ-1 is neuroprotective due to cysteinesulfinic acid-driven mitochondrial localization. Proceedings of the National Academy of Sciences of the United States of America 101, 9103-9108

6. Junn, E., Jang, W. H., Zhao, X., Jeong, B. S., and Mouradian, M. M. (2009) Mitochondrial localization of DJ-1 leads to enhanced neuroprotection. J Neurosci Res 87, 123-129

7. Cali, T., Ottolini, D., Soriano, M. E., and Brini, M. (2015) A new split-GFP-based probe reveals DJ-1 translocation into the mitochondrial matrix to sustain ATP synthesis upon nutrient deprivation. Human molecular genetics 24, 1045-1060

8. Shadrach, K. G., Rayborn, M. E., Hollyfield, J. G., and Bonilha, V. L. (2013) DJ-1dependent regulation of oxidative stress in the retinal pigment epithelium (RPE). PLoS One 8, e67983

9. Taira, T., Saito, Y., Niki, T., Iguchi-Ariga, S. M., Takahashi, K., and Ariga, H. (2004) DJ-1 has a role in antioxidative stress to prevent cell death. EMBO Rep 5, 213218

10. Nagakubo, D., Taira, T., Kitaura, H., Ikeda, M., Tamai, K., Iguchi-Ariga, S. M., and Ariga, H. (1997) DJ-1, a novel oncogene which transforms mouse NIH3T3 cells in cooperation with ras. Biochem Biophys Res Commun 231, 509-513

11. Le Naour, F., Misek, D. E., Krause, M. C., Deneux, L., Giordano, T. J., Scholl, S., and Hanash, S. M. (2001) Proteomics-based identification of RS/DJ-1 as a novel circulating tumor antigen in breast cancer. Clin Cancer Res 7, 3328-3335

12. MacKeigan, J. P., Clements, C. M., Lich, J. D., Pope, R. M., Hod, Y., and Ting, J. P. (2003) Proteomic profiling drug-induced apoptosis in non-small cell lung carcinoma: identification of RS/DJ-1 and RhoGDlalpha. Cancer Res 63, 69286934

13. Hod, Y. (2004) Differential control of apoptosis by DJ-1 in prostate benign and cancer cells. J Cell Biochem 92, 1221-1233

14. Cao, J., Chen, X., Ying, M., He, Q., and Yang, B. (2017) DJ-1 as a Therapeutic Target Against Cancer. Adv Exp Med Biol 1037, 203-222

15. Bahmed, K., Boukhenouna, S., Karim, L., Andrews, T., Lin, J., Powers, R., Wilson, M. A., Lin, C. R., Messier, E., Reisdorph, N., Powell, R. L., Tang, H. Y., Mason, R. J., Criner, G. J., and Kosmider, B. (2019) The effect of cysteine oxidation on DJ-1 cytoprotective function in human alveolar type II cells. Cell Death Dis 10, 638

16. Bahmed, K., Messier, E. M., Zhou, W., Tuder, R. M., Freed, C. R., Chu, H. W., Kelsen, S. G., Bowler, R. P., Mason, R. J., and Kosmider, B. (2016) DJ-1 Modulates Nuclear Erythroid 2-Related Factor-2-Mediated Protection in Human Primary Alveolar Type II Cells in Smokers. Am J Respir Cell Mol Biol 55, 439-449

17. Martin-Nieto, J., Uribe, M. L., Esteve-Rudd, J., Herrero, M. T., and Campello, L. (2019) A role for DJ-1 against oxidative stress in the mammalian retina. Neurosci Lett 708, 134361

18. Cuevas, S., Zhang, Y., Yang, Y., Escano, C., Asico, L., Jones, J. E., Armando, I., and Jose, P. A. (2012) Role of renal DJ-1 in the pathogenesis of hypertension associated with increased reactive oxygen species production. Hypertension 59 , 446-452 
19. Eltoweissy, M., Muller, G. A., Bibi, A., Nguye, P. V., Dihazi, G. H., Muller, C. A., and Dihazi, H. (2011) Proteomics analysis identifies PARK7 as an important player for renal cell resistance and survival under oxidative stress. Mol Biosyst 7, 12771288

20. Waak, J., Weber, S. S., Gorner, K., Schall, C., Ichijo, H., Stehle, T., and Kahle, P. J. (2009) Oxidizable residues mediating protein stability and cytoprotective interaction of DJ-1 with apoptosis signal-regulating kinase 1. J Biol Chem 284, 14245-14257

21. Xu, S., Yang, X., Qian, Y., and Xiao, Q. (2018) Parkinson's disease-related DJ-1 modulates the expression of uncoupling protein 4 against oxidative stress. $J$ Neurochem 145, 312-322

22. Kinumi, T., Kimata, J., Taira, T., Ariga, H., and Niki, E. (2004) Cysteine-106 of DJ1 is the most sensitive cysteine residue to hydrogen peroxide-mediated oxidation in vivo in human umbilical vein endothelial cells. Biochem Biophys Res Commun 317, 722-728

23. Mita, Y., Kataoka, Y., Saito, Y., Kashi, T., Hayashi, K., Iwasaki, A., Imanishi, T., Miyasaka, T., and Noguchi, N. (2018) Distribution of oxidized DJ-1 in Parkinson's disease-related sites in the brain and in the peripheral tissues: effects of aging and a neurotoxin. Sci Rep 8, 12056

24. Oswald, M. C., Brooks, P. S., Zwart, M. F., Mukherjee, A., West, R. J., Giachello, C. N., Morarach, K., Baines, R. A., Sweeney, S. T., and Landgraf, M. (2018) Reactive oxygen species regulate activity-dependent neuronal plasticity in Drosophila. Elife 7

25. Cao, J., Ying, M., Xie, N., Lin, G., Dong, R., Zhang, J., Yan, H., Yang, X., He, Q., and Yang, B. (2014) The oxidation states of DJ-1 dictate the cell fate in response to oxidative stress triggered by 4-hpr: autophagy or apoptosis? Antioxid Redox Signal 21, 1443-1459

26. Atieh, T. B., Roth, J., Yang, X., Hoop, C. L., and Baum, J. (2021) DJ-1 Acts as a Scavenger of alpha-Synuclein Oligomers and Restores Monomeric Glycated alpha-Synuclein. Biomolecules 11

27. Zhou, W., Zhu, M., Wilson, M. A., Petsko, G. A., and Fink, A. L. (2006) The oxidation state of DJ-1 regulates its chaperone activity toward alpha-synuclein. $J$ Mol Biol 356, 1036-1048

28. Kumar, R., Kumar, S., Hanpude, P., Singh, A. K., Johari, T., Majumder, S., and Maiti, T. K. (2019) Partially oxidized DJ-1 inhibits alpha-synuclein nucleation and remodels mature alpha-synuclein fibrils in vitro. Commun Biol 2, 395

29. Mitsugi, H., Niki, T., Takahashi-Niki, K., Tanimura, K., Yoshizawa-Kumagaye, K., Tsunemi, M., Iguchi-Ariga, S. M., and Ariga, H. (2013) Identification of the recognition sequence and target proteins for DJ-1 protease. FEBS Lett 587, 24932499

30. Olzmann, J. A., Brown, K., Wilkinson, K. D., Rees, H. D., Huai, Q., Ke, H., Levey, A. I., Li, L., and Chin, L. S. (2004) Familial Parkinson's disease-associated L166P mutation disrupts DJ-1 protein folding and function. J Biol Chem 279, 8506-8515

31. Vazquez-Mayorga, E., Diaz-Sanchez, A. G., Dagda, R. K., Dominguez-Solis, C. A., Dagda, R. Y., Coronado-Ramirez, C. K., and Martinez-Martinez, A. (2016) Novel Redox-Dependent Esterase Activity (EC 3.1.1.2) for DJ-1: Implications for Parkinson's Disease. Int J Mol Sci 17

32. Lee, S. J., Kim, S. J., Kim, I. K., Ko, J., Jeong, C. S., Kim, G. H., Park, C., Kang, S. O., Suh, P. G., Lee, H. S., and Cha, S. S. (2003) Crystal structures of human DJ-1 and Escherichia coli Hsp31, which share an evolutionarily conserved domain. J Biol Chem 278, 44552-44559 
33. Shendelman, S., Jonason, A., Martinat, C., Leete, T., and Abeliovich, A. (2004) DJ-1 is a redox-dependent molecular chaperone that inhibits alpha-synuclein aggregate formation. PLoS Biol 2, e362

34. Choi, M. S., Nakamura, T., Cho, S. J., Han, X., Holland, E. A., Qu, J., Petsko, G. A., Yates, J. R., 3rd, Liddington, R. C., and Lipton, S. A. (2014) Transnitrosylation from DJ-1 to PTEN attenuates neuronal cell death in parkinson's disease models. $J$ Neurosci 34, 15123-15131

35. van der Brug, M. P., Blackinton, J., Chandran, J., Hao, L. Y., Lal, A., MazanMamczarz, K., Martindale, J., Xie, C., Ahmad, R., Thomas, K. J., Beilina, A., Gibbs, J. R., Ding, J., Myers, A. J., Zhan, M., Cai, H., Bonini, N. M., Gorospe, M., and Cookson, M. R. (2008) RNA binding activity of the recessive parkinsonism protein DJ-1 supports involvement in multiple cellular pathways. Proceedings of the National Academy of Sciences of the United States of America 105, 10244-10249

36. Hod, Y., Pentyala, S. N., Whyard, T. C., and El-Maghrabi, M. R. (1999) Identification and characterization of a novel protein that regulates RNA-protein interaction. J Cell Biochem 72, 435-444

37. Heremans, I. P., Caligiore, F., Gerin, I., Bury, M., Lutz, M., Graff, J., Stroobant, V., Vertommen, D., Teleman, A. A., Van Schaftingen, E., and Bommer, G. T. (2022) Parkinson's disease protein PARK7 prevents metabolite and protein damage caused by a glycolytic metabolite. Proceedings of the National Academy of Sciences of the United States of America 119

38. Witt, A. C., Lakshminarasimhan, M., Remington, B. C., Hasim, S., Pozharski, E., and Wilson, M. A. (2008) Cysteine pKa depression by a protonated glutamic acid in human DJ-1. Biochemistry 47, 7430-7440

39. Wei, Y., Ringe, D., Wilson, M. A., and Ondrechen, M. J. (2007) Identification of functional subclasses in the DJ-1 superfamily proteins. PLoS Comput Biol 3, e10

40. Halio, S. B., Blumentals, II, Short, S. A., Merrill, B. M., and Kelly, R. M. (1996) Sequence, expression in Escherichia coli, and analysis of the gene encoding a novel intracellular protease (Pfpl) from the hyperthermophilic archaeon Pyrococcus furiosus. J Bacteriol 178, 2605-2612

41. Du, X., Choi, I. G., Kim, R., Wang, W., Jancarik, J., Yokota, H., and Kim, S. H. (2000) Crystal structure of an intracellular protease from Pyrococcus horikoshii at 2-A resolution. Proceedings of the National Academy of Sciences of the United States of America 97, 14079-14084

42. Goda, M., Hashimoto, Y., Shimizu, S., and Kobayashi, M. (2001) Discovery of a novel enzyme, isonitrile hydratase, involved in nitrogen-carbon triple bond cleavage. J Biol Chem 276, 23480-23485

43. Goda, M., Hashimoto, Y., Takase, M., Herai, S., Iwahara, Y., Higashibata, H., and Kobayashi, M. (2002) Isonitrile hydratase from Pseudomonas putida N19-2. Cloning, sequencing, gene expression, and identification of its active acid residue. J Biol Chem 277, 45860-45865

44. Lakshminarasimhan, M., Madzelan, P., Nan, R., Milkovic, N. M., and Wilson, M. A. (2010) Evolution of new enzymatic function by structural modulation of cysteine reactivity in Pseudomonas fluorescens isocyanide hydratase. J Biol Chem 285, 29651-29661

45. Subedi, K. P., Choi, D., Kim, I., Min, B., and Park, C. (2011) Hsp31 of Escherichia coli K-12 is glyoxalase III. Molecular microbiology 81, 926-936

46. Chen, J., Li, L., and Chin, L. S. (2010) Parkinson disease protein DJ-1 converts from a zymogen to a protease by carboxyl-terminal cleavage. Human molecular genetics 19, 2395-2408 
47. Andres-Mateos, E., Perier, C., Zhang, L., Blanchard-Fillion, B., Greco, T. M., Thomas, B., Ko, H. S., Sasaki, M., Ischiropoulos, H., Przedborski, S., Dawson, T. M., and Dawson, V. L. (2007) DJ-1 gene deletion reveals that DJ-1 is an atypical peroxiredoxin-like peroxidase. Proceedings of the National Academy of Sciences of the United States of America 104, 14807-14812

48. Lee, J. Y., Song, J., Kwon, K., Jang, S., Kim, C., Baek, K., Kim, J., and Park, C. (2012) Human DJ-1 and its homologs are novel glyoxalases. Human molecular genetics 21, 3215-3225

49. Kwon, K., Choi, D., Hyun, J. K., Jung, H. S., Baek, K., and Park, C. (2013) Novel glyoxalases from Arabidopsis thaliana. The FEBS journal 280, 3328-3339

50. Hasim, S., Hussin, N. A., Alomar, F., Bidasee, K. R., Nickerson, K. W., and Wilson, M. A. (2014) A glutathione-independent glyoxalase of the DJ-1 superfamily plays an important role in managing metabolically generated methylglyoxal in Candida albicans. J Biol Chem 289, 1662-1674

51. Zhao, Q., Su, Y., Wang, Z., Chen, C., Wu, T., and Huang, Y. (2014) Identification of glutathione (GSH)-independent glyoxalase III from Schizosaccharomyces pombe. BMC Evol Biol 14, 86

52. Richarme, G., Abdallah, J., Mathas, N., Gautier, V., and Dairou, J. (2018) Further characterization of the Maillard deglycase DJ-1 and its prokaryotic homologs, deglycase 1/Hsp31, deglycase 2/YhbO, and deglycase 3/YajL. Biochem Biophys Res Commun 503, 703-709

53. Richarme, G., and Dairou, J. (2017) Parkinsonism-associated protein DJ-1 is a bona fide deglycase. Biochem Biophys Res Commun 483, 387-391

54. Richarme, G., Liu, C., Mihoub, M., Abdallah, J., Leger, T., Joly, N., Liebart, J. C., Jurkunas, U. V., Nadal, M., Bouloc, P., Dairou, J., and Lamouri, A. (2017) Guanine glycation repair by DJ-1/Park7 and its bacterial homologs. Science 357, 208-211

55. Richarme, G., Mihoub, M., Dairou, J., Bui, L. C., Leger, T., and Lamouri, A. (2015) Parkinsonism-associated protein DJ-1/Park7 is a major protein deglycase that repairs methylglyoxal- and glyoxal-glycated cysteine, arginine, and lysine residues. J Biol Chem 290, 1885-1897

56. Matsuda, N., Kimura, M., Queliconi, B. B., Kojima, W., Mishima, M., Takagi, K., Koyano, F., Yamano, K., Mizushima, T., Ito, Y., and Tanaka, K. (2017) Parkinson's disease-related DJ-1 functions in thiol quality control against aldehyde attack in vitro. Sci Rep 7, 12816

57. Zheng, Q., Omans, N. D., Leicher, R., Osunsade, A., Agustinus, A. S., FinkinGroner, E., D'Ambrosio, H., Liu, B., Chandarlapaty, S., Liu, S., and David, Y. (2019) Reversible histone glycation is associated with disease-related changes in chromatin architecture. Nat Commun 10, 1289

58. Sharma, N., Rao, S. P., and Kalivendi, S. V. (2019) The deglycase activity of DJ1 mitigates alpha-synuclein glycation and aggregation in dopaminergic cells: Role of oxidative stress mediated downregulation of DJ-1 in Parkinson's disease. Free Radic Biol Med 135, 28-37

59. Thornalley, P. J. (1990) The glyoxalase system: new developments towards functional characterization of a metabolic pathway fundamental to biological life. The Biochemical journal 269, 1-11

60. Marmstal, E., Aronsson, A. C., and Mannervik, B. (1979) Comparison of glyoxalase I purified from yeast (Saccharomyces cerevisiae) with the enzyme from mammalian sources. The Biochemical journal 183, 23-30

61. Andreeva, A., Bekkhozhin, Z., Omertassova, N., Baizhumanov, T., Yeltay, G., Akhmetali, M., Toibazar, D., and Utepbergenov, D. (2019) The apparent deglycase 
activity of DJ-1 results from the conversion of free methylglyoxal present in fast equilibrium with hemithioacetals and hemiaminals. J Biol Chem 294, 18863-18872

62. Galligan, J. J., Wepy, J. A., Streeter, M. D., Kingsley, P. J., Mitchener, M. M., Wauchope, O. R., Beavers, W. N., Rose, K. L., Wang, T., Spiegel, D. A., and Marnett, L. J. (2018) Methylglyoxal-derived posttranslational arginine modifications are abundant histone marks. Proceedings of the National Academy of Sciences of the United States of America 115, 9228-9233

63. Pfaff, D. H., Fleming, T., Nawroth, P., and Teleman, A. A. (2017) Evidence Against a Role for the Parkinsonism-associated Protein DJ-1 in Methylglyoxal Detoxification. J Biol Chem 292, 685-690

64. Natkanska, U., Skoneczna, A., Sienko, M., and Skoneczny, M. (2017) The budding yeast orthologue of Parkinson's disease-associated DJ-1 is a multi-stress response protein protecting cells against toxic glycolytic products. Biochim Biophys Acta Mol Cell Res 1864, 39-50

65. Jun, Y. W., and Kool, E. T. (2020) Small Substrate or Large? Debate Over the Mechanism of Glycation Adduct Repair by DJ-1. Cell Chem Biol 27, 1117-1123

66. Moraru, A., Wiederstein, J., Pfaff, D., Fleming, T., Miller, A. K., Nawroth, P., and Teleman, A. A. (2018) Elevated Levels of the Reactive Metabolite Methylglyoxal Recapitulate Progression of Type 2 Diabetes. Cell Metab 27, 926-934 e928

67. Shuck, S. C., Wuenschell, G. E., and Termini, J. S. (2018) Product Studies and Mechanistic Analysis of the Reaction of Methylglyoxal with Deoxyguanosine. Chemical research in toxicology 31, 105-115

68. Lo, T. W., Westwood, M. E., McLellan, A. C., Selwood, T., and Thornalley, P. J. (1994) Binding and modification of proteins by methylglyoxal under physiological conditions. A kinetic and mechanistic study with $\mathrm{N}$ alpha-acetylarginine, $\mathrm{N}$ alphaacetylcysteine, and $\mathrm{N}$ alpha-acetyllysine, and bovine serum albumin. J Biol Chem 269, 32299-32305

69. Clugston, S. L., Barnard, J. F., Kinach, R., Miedema, D., Ruman, R., Daub, E., and Honek, J. F. (1998) Overproduction and characterization of a dimeric non-zinc glyoxalase I from Escherichia coli: evidence for optimal activation by nickel ions. Biochemistry 37, 8754-8763

70. Blackinton, J., Lakshminarasimhan, M., Thomas, K. J., Ahmad, R., Greggio, E., Raza, A. S., Cookson, M. R., and Wilson, M. A. (2009) Formation of a stabilized cysteine sulfinic acid is critical for the mitochondrial function of the parkinsonism protein DJ-1. J Biol Chem 284, 6476-6485

71. Choi, D., Kim, J., Ha, S., Kwon, K., Kim, E. H., Lee, H. Y., Ryu, K. S., and Park, C. (2014) Stereospecific mechanism of DJ-1 glyoxalases inferred from their hemithioacetal-containing crystal structures. The FEBS journal 281, 5447-5462

72. Mazza, M. C., Beilina, A., Roosen, D. A., Hauser, D., and Cookson, M. R. (2021) Generation of iPSC line from a Parkinson patient with PARK7 mutation and CRISPR-edited Gibco human episomal iPSC line to mimic PARK7 mutation. Stem Cell Res 55, 102506

73. Griffith, O. W., and Meister, A. (1979) Potent and specific inhibition of glutathione synthesis by buthionine sulfoximine (S-n-butyl homocysteine sulfoximine). J Biol Chem 254, 7558-7560

74. Kim, R. H., Peters, M., Jang, Y., Shi, W., Pintilie, M., Fletcher, G. C., DeLuca, C., Liepa, J., Zhou, L., Snow, B., Binari, R. C., Manoukian, A. S., Bray, M. R., Liu, F. F., Tsao, M. S., and Mak, T. W. (2005) DJ-1, a novel regulator of the tumor suppressor PTEN. Cancer Cell 7, 263-273

75. Clements, C. M., McNally, R. S., Conti, B. J., Mak, T. W., and Ting, J. P. (2006) DJ-1, a cancer- and Parkinson's disease-associated protein, stabilizes the 
antioxidant transcriptional master regulator Nrf2. Proceedings of the National Academy of Sciences of the United States of America 103, 15091-15096

76. Bar-Even, A., Noor, E., Savir, Y., Liebermeister, W., Davidi, D., Tawfik, D. S., and Milo, R. (2011) The moderately efficient enzyme: evolutionary and physicochemical trends shaping enzyme parameters. Biochemistry 50, 4402-4410

77. Inoue, Y., and Kimura, A. (1996) Identification of the structural gene for glyoxalase I from Saccharomyces cerevisiae. J Biol Chem 271, 25958-25965

78. Aslam, K., and Hazbun, T. R. (2016) Hsp31, a member of the DJ-1 superfamily, is a multitasking stress responder with chaperone activity. Prion 10, 103-111

79. Mulikova, T., Bekkhozhin, Z., Abdirassil, A., and Utepbergenov, D. (2021) A continuous spectrophotometric assay for glutathione-independent glyoxalases. Analytical biochemistry 630, 114317

80. Lin, J., Prahlad, J., and Wilson, M. A. (2012) Conservation of oxidative protein stabilization in an insect homologue of parkinsonism-associated protein DJ-1. Biochemistry 51, 3799-3807

81. Johnson, K. A., Simpson, Z. B., and Blom, T. (2009) Global kinetic explorer: a new computer program for dynamic simulation and fitting of kinetic data. Anal Biochem 387, 20-29

82. Johnson, K. A., Simpson, Z. B., and Blom, T. (2009) FitSpace explorer: an algorithm to evaluate multidimensional parameter space in fitting kinetic data. Anal Biochem 387, 30-41

83. Zepeta-Flores, N., Valverde, M., Lopez-Saavedra, A., and Rojas, E. (2018) Glutathione depletion triggers actin cytoskeleton changes via actin-binding proteins. Genet Mol Biol 41, 475-487

84. Jaramillo, R., Shuck, S. C., Chan, Y. S., Liu, X., Bates, S. E., Lim, P. P., Tamae, D., Lacoste, S., O'Connor, T. R., and Termini, J. (2017) DNA Advanced Glycation End Products (DNA-AGEs) Are Elevated in Urine and Tissue in an Animal Model of Type 2 Diabetes. Chemical research in toxicology 30, 689-698 
Table 1. DJ-1 kinetic parameters from experiment

\begin{tabular}{|llll|}
\hline Substrate & $\mathbf{k}_{\text {cat }}\left(\mathbf{s}^{-1}\right)$ & $\mathbf{K}_{\mathbf{M}}(\mathbf{M})$ & $\mathbf{k}_{\text {cat }} / \mathbf{K}_{\mathbf{M}}\left(\mathbf{M}^{-1} \mathbf{s}^{-1}\right)$ \\
\hline MG & $7.3(2) \times 10^{-2}$ & $3.47(34) \times 10^{-4}$ & 210 \\
MG-NAC & $8.7(3) \times 10^{-3}$ & $5.80(11) \times 10^{-5}$ & 150 \\
MG-GSH & $6.7(3) \times 10^{-3}$ & $1.42(28) \times 10^{-4}$ & 47 \\
& & & \\
MG-CoA & $6.8(7) \times 10^{-3}$ & $\begin{array}{l}1.44(64) \\
\text { X10 }\end{array}$ & 47 \\
& & & \\
\hline
\end{tabular}

Table 2. DJ-1 kinetic parameters with MG substrate from kinetic simulation aLower and upper boundaries were determined by a published algorithm that varies the rate constants to find values that fall within a 0.83 relative error to the

\begin{tabular}{|llll|}
\hline Rate constant & Best-fit value & $\begin{array}{l}\text { aLower } \\
\text { boundary }\end{array}$ & aUpper boundary \\
\hline $\mathrm{k}_{1}\left(\mathrm{M}^{-1} \mathrm{sec}^{-1}\right)$ & 360 & 123.83 & $11,466.67$ \\
$\mathrm{k}_{-1}\left(\mathrm{sec}^{-1}\right)$ & $7.82 \times 10^{-2}$ & $2.62 \times 10^{-12}$ & 4.13 \\
$\mathrm{k}_{2}\left(\mathrm{k}_{\mathrm{cat}}\right)\left(\mathrm{sec}^{-1}\right)$ & $4.02 \times 10^{-2}$ & $3.82 \times 10^{-2}$ & $4.27 \times 10^{-2}$ \\
${ }^{2}$ Calculated $\mathrm{K}_{\mathrm{M}}$ & $3.29 \times 10^{-4}$ & $\mathrm{~d}^{2} 2.76 \times 10^{-4}$ & ${ }^{\mathrm{d}} 3.63 \times 10^{-4}$ \\
$(\mathrm{M})$ & & & \\
$\mathrm{k}_{3}\left(\mathrm{M}^{-1} \mathrm{sec}^{-1}\right)$ & 3.25 & 1.98 & 104.17 \\
$\mathrm{k}_{-3}\left(\mathrm{sec}^{-1}\right)$ & $6.5 \times 10^{-3}$ & bD & bND \\
\hline
\end{tabular}
best-fit (82).

${ }^{b}$ KinTek global explorer software only estimates one rate constant when the ratio is being constrained by the equilibrium constant $\left(500 \mathrm{M}^{-1}\right)$.

'The $\mathrm{K}_{\mathrm{M}}$ was calculated using the definition $\left(K_{m}=\frac{k_{-1}+k_{2}}{k_{1}}\right)$

dLower and upper boundaries are not determined directly in KinTek global software for steady-state constants therefore they were calculated from the collection of rate constants that fit the data within a 0.83 relative error from the best-fit. 
Figure 1

A

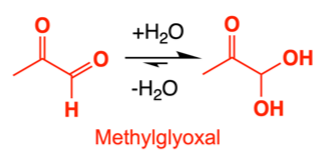<smiles>COC(=O)C(C)Nc1nc2c(ncn2C2CC(O)C(CO)O2)c(=O)[nH]1</smiles>

DNA adduct Carboxyethyl-dG (CEdG)<smiles>CC(Nc1nc2c(ncn2[C@@H]2C[C@H](O)[C@@H](O)O2)c(=O)[nH]1)C(=O)O</smiles>

RNA adduct Carboxyethyl-Guanosine (CEG)<smiles>CC(NCCCCC(N)C(=O)O)C(=O)O</smiles>

Lysine adduct Carboxyethyl-Lysine (CEL)

B

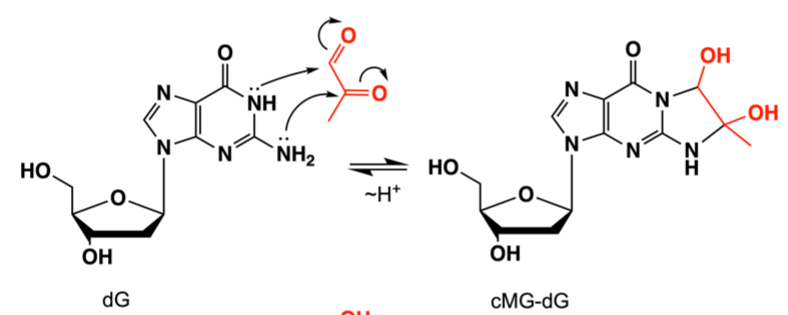

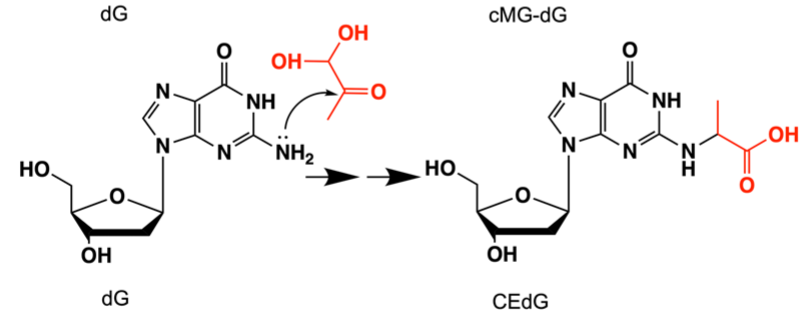

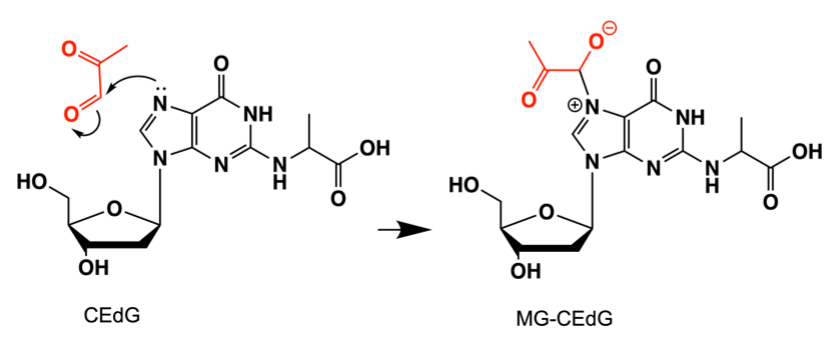

Figure 1. Adduct species generated by methylglyoxal (MG). (A) shows the hydration equilibrium reaction of $M G$ (red), which lies to the right in aqueous solution. MG can form stable adducts with both guanine and lysine. (B) shows abbreviated mechanisms for MG modification of deoxyguanosine to form three adducts. Only cMG-dG is reversible, as indicated by arrows. 
Figure 2

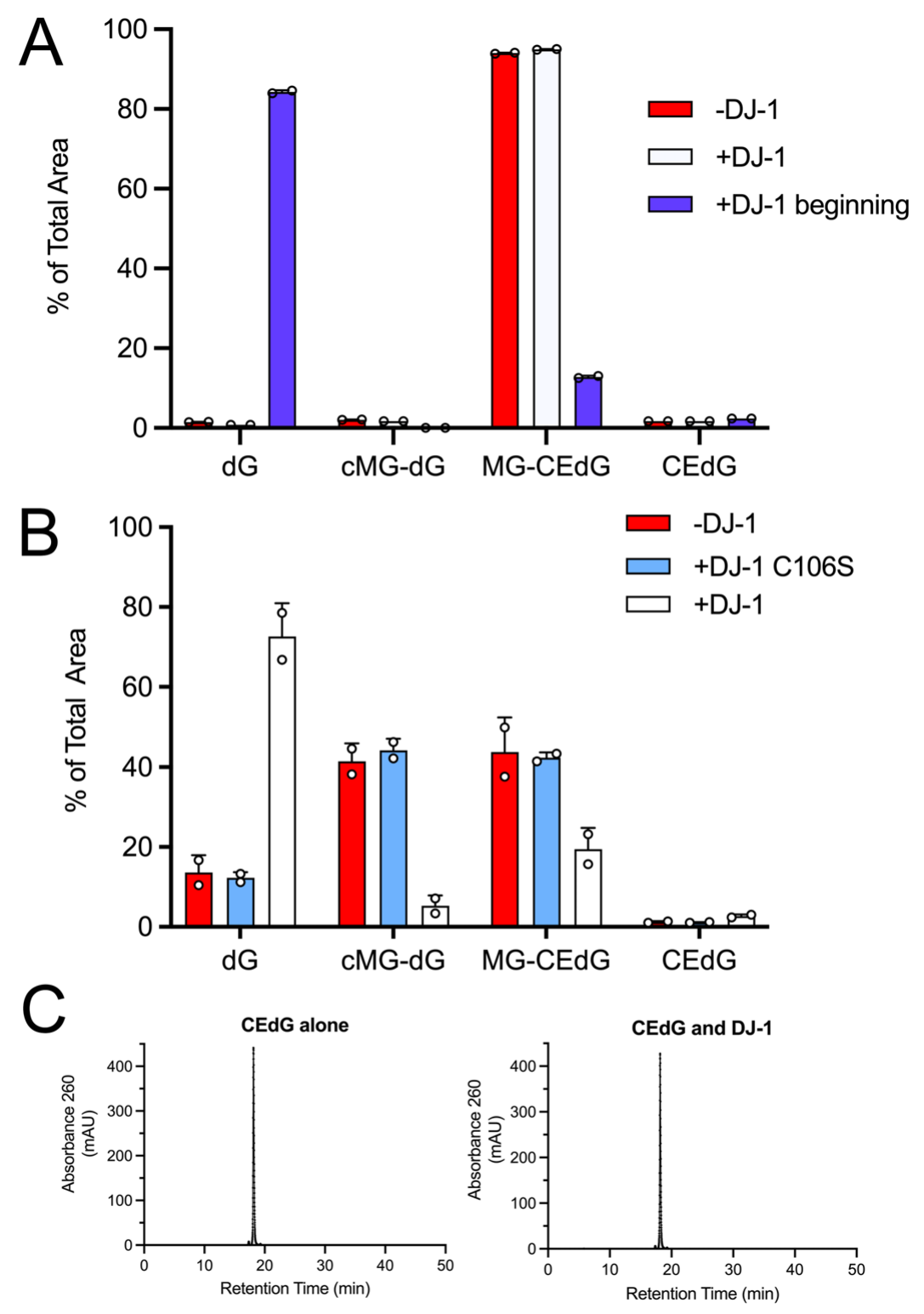

Figure 2. DJ-1 can only repair reversible adducts of MG and guanine in vitro. (A) Addition of DJ-1 at the same time as MG and dG (+DJ-1 beginning; blue) reduces levels of both reversible cMG-dG and irreversible MG-CEdG adducts, while addition of DJ-1 after one hour of preincubation of $M G$ and $d G$ (+DJ-1; white) results in an accumulation of irreversible MG-CEdG and cannot restore unmodified dG. (B) The C106S mutant (cyan), which removes the catalytic thiolate nucleophile, is inactive and cannot prevent dG modification. Only catalytically active DJ-1 prevents formation of dG adducts when added at the same time as MG. (C) Addition of DJ-1 results in no change in the HPLC retention time of purified CEdG, an irreversible adduct. In all panels, each measurement is shown as a circle with standard error of the mean shown in error bars. 
Figure 3
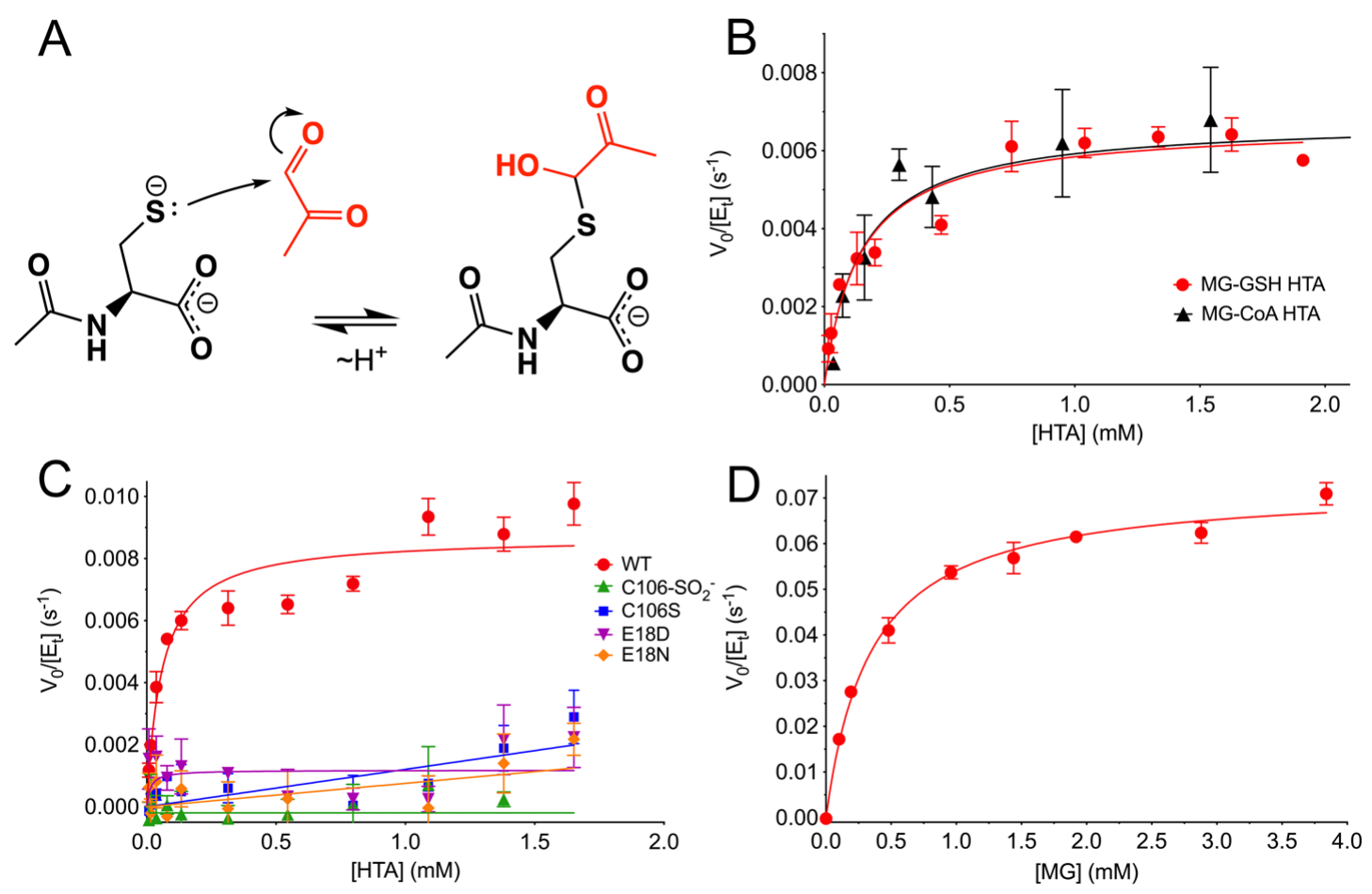

Figure 3. DJ-1 has apparent hemithioacetal deglycase and glyoxalase activities in vitro. (A) Mechanism of formation of hemiacetal formation by NAC (black) and MG (red). The hemithioacetal is reversible, as indicated by the arrows. (B) Steady-state enzyme kinetics of DJ-1 acting on the MG-glutathione (MG-GSH; red) and MG-coenzyme A (MGCoA; black) hemitioacetal substrates. (C) Steady-state kinetics of DJ-1 acting on the MG$\mathrm{N}$-acetyl cysteine (MG-NAC) hemithioacetal substrate. Wild-type (WT) enzyme is in red, and mutants and oxidative modification are shown in the inset legend with the indicated symbols and colors. Only WT DJ-1 is active enough to be reliably fitted using the Michaelis-Menten model (solid lines). (D) Steady-state kinetics of DJ-1 glyoxalase activity against $M G$ as substrate. In panels $B-D$, initial velocity $\left(V_{0}\right)$ is divided by total enzyme concentration $\left(\left[E_{t}\right]\right)$ on the $Y$-axis, rates were measured a minimum of three times with standard deviation shown in bars, and the fitted Michaelis-Menten curves are shown as solid lines. 


\section{Figure 4}
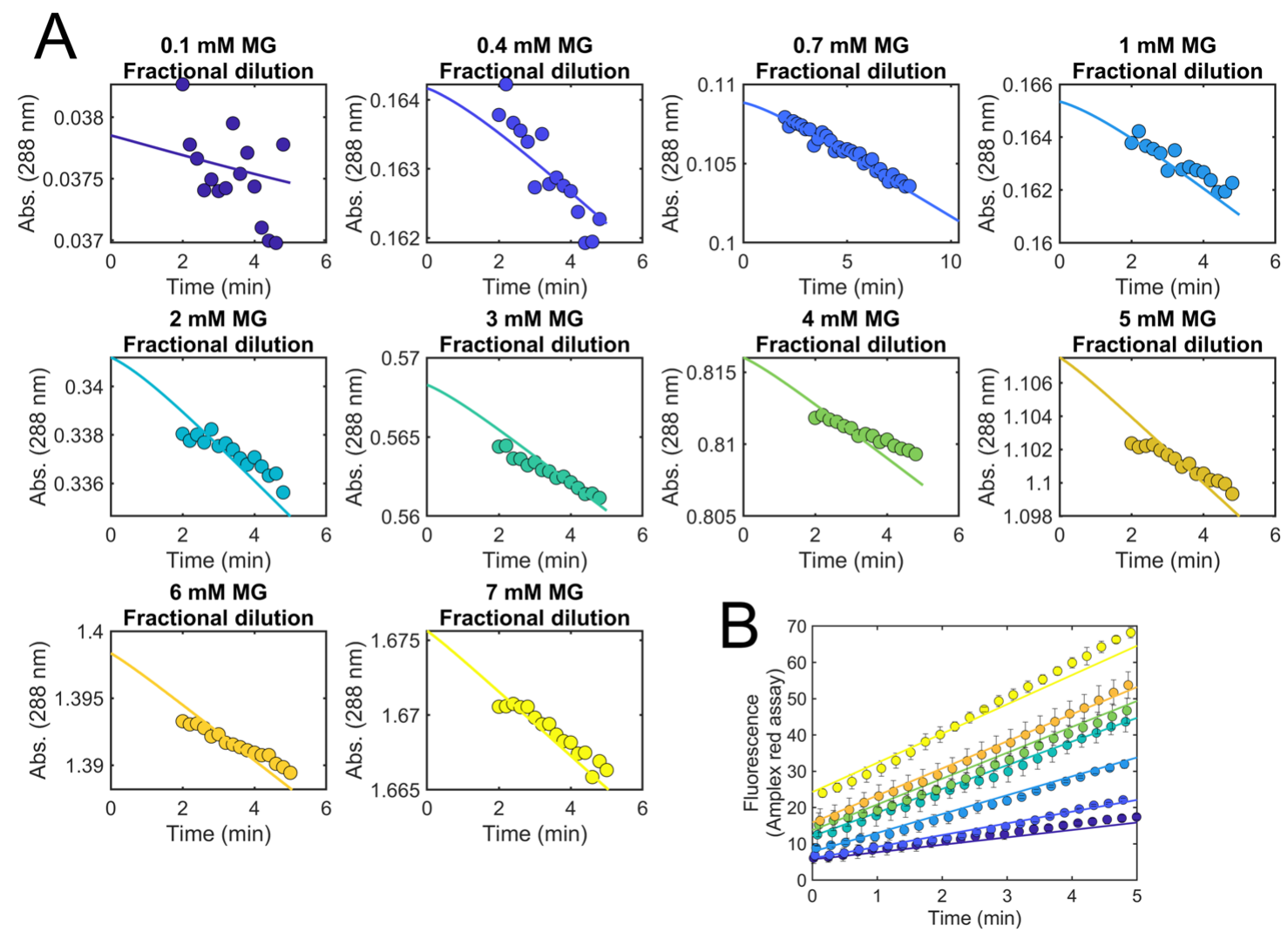

Figure 4. Kinetic simulation of DJ-1 deglycase and glyoxalase activities. (A) Experimental progress curves for loss of MG-NAC hemithioacetal signal at $288 \mathrm{~nm}$ (colored dots) are superimposed with kinetic modeling results (solid lines) for various concentrations of total MG concentration at initial dilution. The simulation requires only a DJ-1 glyoxalase activity to produce good fits to the apparent deglycase activity. (B) Experimentally measured DJ-1 glyoxalase activity against various concentrations of MG (colored dots) is well-modeled by the kinetic simulation (solid lines) whose rate constants also explain the apparent deglycase activities in (A). 


\section{Figure 5}
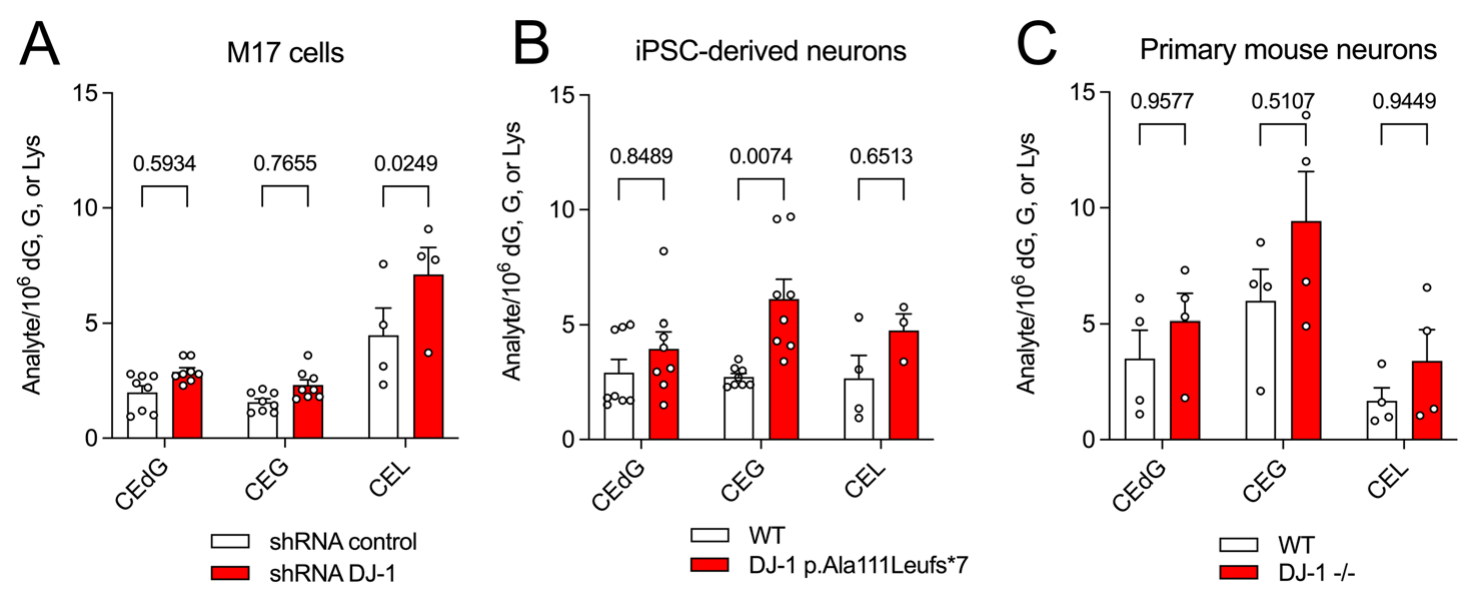

Figure 5. DJ-1 has a modest impact on cellular concentrations of irreversible glycation products in neurons. In all panels, isotope-dilution mass spectrometry was used to obtain relative concentrations of modified vs. unmodified dG, G, or Lys. Two-way ANOVA was used for statistical analysis with $p$ values shown. Small but consistent elevations in glycated products were observed in (A) siRNA knockdown of DJ-1 in immortalized M17 neuroblastoma, (B) iPSC-derived neurons derived from wild-type (WT) cells and cell bearing a DJ-1 missense mutation that eliminates protein (DJ-1 p.Ala111Leufs ${ }^{*}$ ) and (C) primary neurons from WT and DJ-1 $1^{-/-}$mice. Each measurement is shown as a circle with standard error of the mean shown in error bars. 


\section{Figure 6}
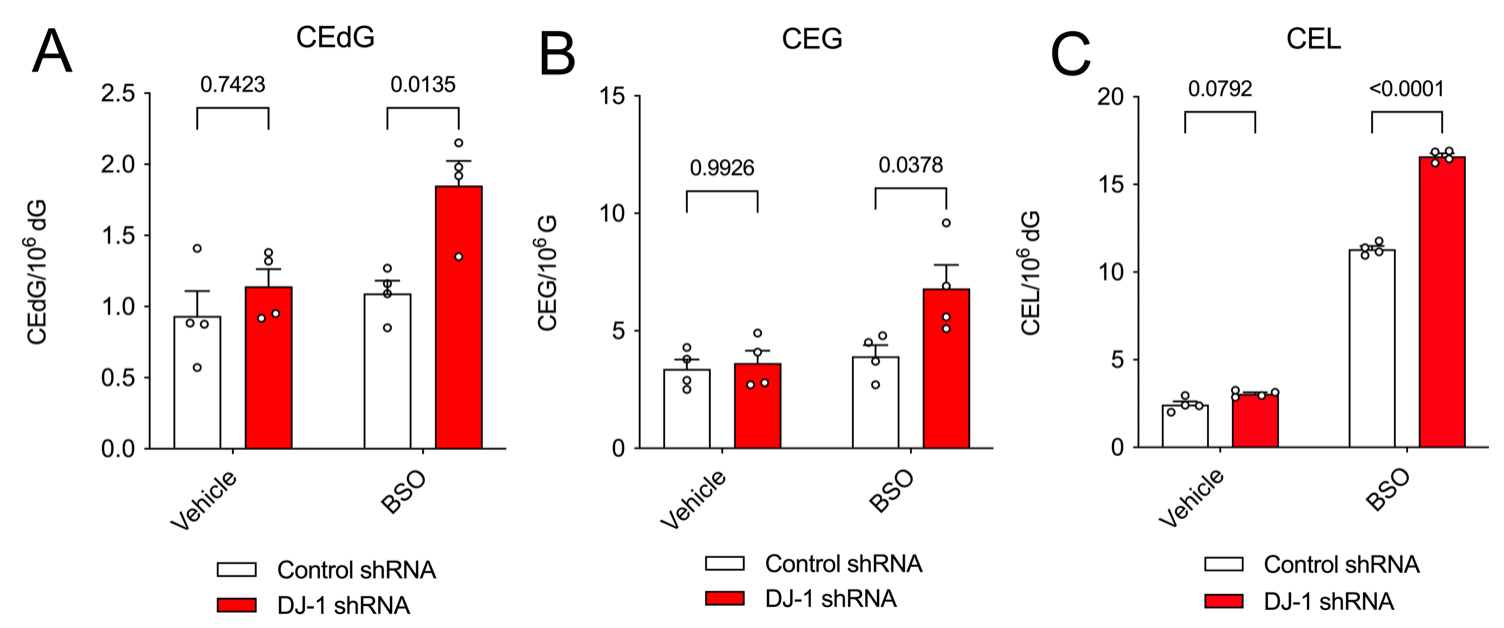

Figure 6. Chemical reduction in cellular glutathione enhances the glycation burden of DJ-1 knockdown M17 cells. In all panels, isotope-dilution mass spectrometry was used to obtain relative concentrations of modified vs. unmodified dG, G, or Lys in cultured M17 neuroblastoma cells. Two-way ANOVA was used for statistical analysis with $p$-values shown. BSO was used to reduce cellular levels of GSH, which is a co-substrate for the dominant glyoxalase Glo1. Administration of BSO enhances the effect of DJ-1 deficiency on CEdG (A), CEG (B) and CEL (C) levels. Each measurement is shown as a circle with standard error of the mean shown in error bars. 


\section{Figure 7}

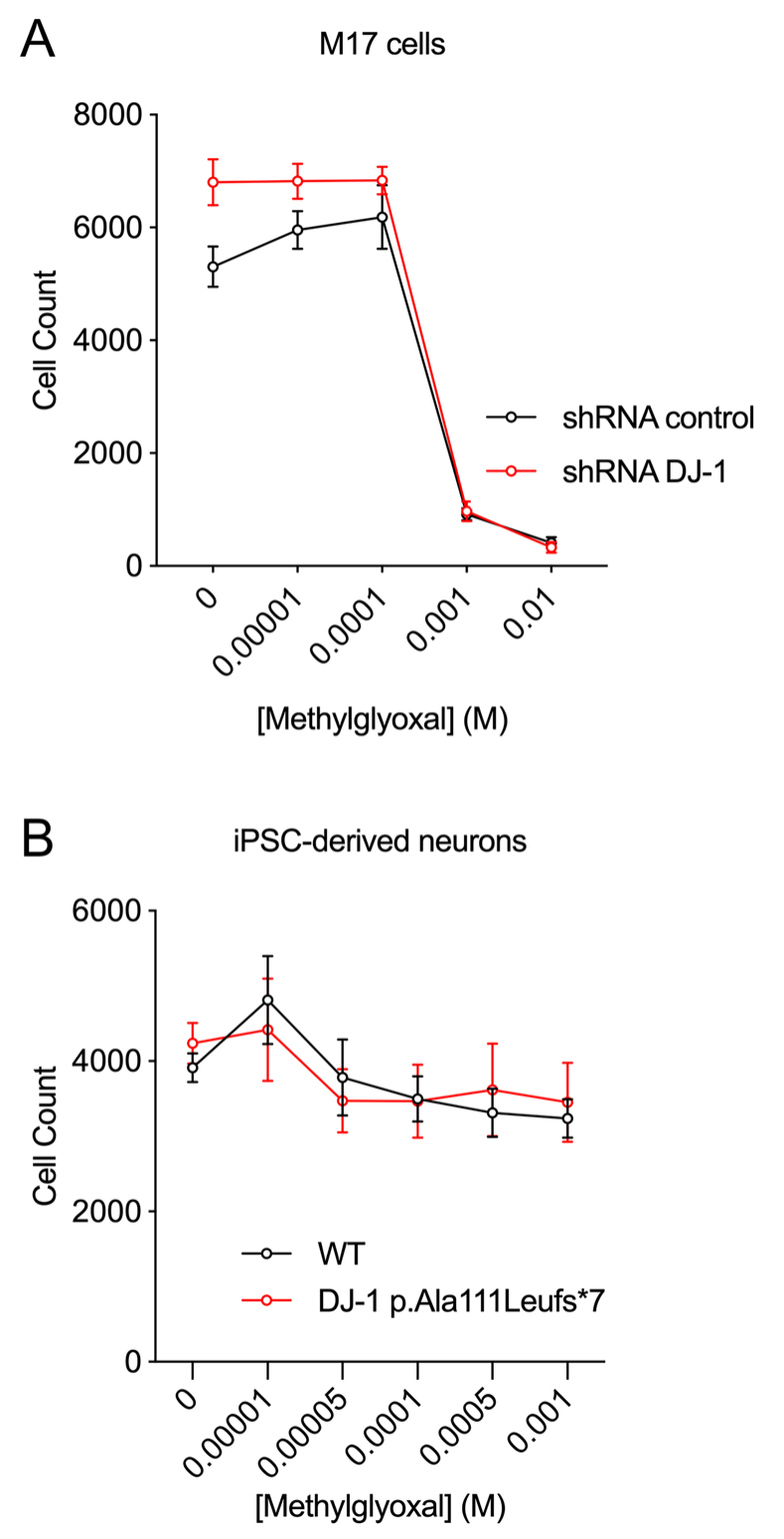

Figure 7. DJ-1 deficiency does not enhance cell death in the presence of exogenous MG. Exogenous MG was added to cultured M17 cells (A) and iPSC-derived neurons (B). No enhancement of cell death was observed when DJ-1 was knocked down with siRNA (A) or absent at the protein level (B). 
bioRxiv preprint doi: https://doi.org/10.1101/2022 02 18.481064; this version posted February 19,2022 . The copyright holder for this preprint (which was not certified by peer review) is the author/funder, who has granted bioRxiv a license to display the preprint in perpetuity. It is made available under aCC-BY-NC-ND 4.0 International license.

\section{Scheme 1}

DJ-1+methylglyoxal $\underset{k_{-1}}{\stackrel{k_{1}}{\longrightarrow}} \begin{aligned} & \text { DJ-1-methylglyoxal } \\ & \text { Michaelis complex }\end{aligned} \stackrel{k_{2}}{\longrightarrow} \mathrm{DJ}-1+$ L-lactate

methylglyoxal+NAC $\underset{k_{-3}}{\stackrel{k_{3}}{\rightleftharpoons}}$ NAC-methylglyoxal hemithioacetal 